\title{
LA DINASTÍA DE LOS SEVEROS Y EL EJÉRCITO
}

\author{
THE SEVERO'S DYNASTY AND THE ARMY
}

\author{
Cesare LetTa* \\ c.letta@sta.unipi.it
}

\begin{abstract}
RESUMEN
Después de una premisa sobre las fuentes principales utilizadas (Casio Dión, Herodiano, Historia Augusta), el analisis del golpe de estado del 193 d. de C., que eliminó a Cómodo y otorgó el poder imperial a Pértinax, muestru que los conspiradores, al escoger a Septimio Severo, Pescenio Nigro y Clodio Albino como gobernadores de las tres provincias más importantes militarmente (Panonia Superior, Siria y Bretaña), se ilusionaban haber elegido a hombres de escaso valor, sin experiencia ni prestigio militar, y por lo tanto incapaces de intentar un pronunciamiento con sus legiones. El análisis de la carrera de Severo antes de su aclamación imperial, mediocre y sin comandos militares significativos, confirma esta conclusión.
\end{abstract}

Palabras clave: Imperio Romano, Ejéreito romano, Dinastia Severo, Septimio Severo

\begin{abstract}
After a premise about the main sources used (Casio Diôn, Herodiano, Historia Augusta), the analysis of the coup d'etat in 193 a. D., which removed Cormodus and gave the imperial power to Pertinax, shows that conspirators, when chose Septimius Severus, Pescenius Niger and Clodius Albinus as governors of the main three provinces (Upper Panonia, Syria and Britain), were illusionated on the election of men with very few courage, without experience or militar prestige and so that unable to try a military uprising with their legions. The analysis of Severus' careet before his imperial acclamation, mediocre and without significative military comands, confirms this conclusion.
\end{abstract}

Keywords: Roman Empire, Roman Army, Severus Dynasty, Septimius Severus

\section{PRÓLOGO}

La época de los Severos (193-235 d. de C.) tiene una importancia fundamental para una exacta comprensión de la transición del principado al dominado (o Bajo Imperio), porque ella cierra definitivamente la fase empezada por los Antoninos y marca un viraje decisivo en el desarrollo del Imperio Romano por lo menos en tres aspectos básicos: 1) el regreso definitivo al principio de la herencia dinástica con el desamparo de la ideologia de los emperadores adoptivos; 2) la instauración de la autocracia militar, que reducia drásticamente el espacio político del senado; 3) el desamparo de la preminencia política, social, económica y sobre todo ideológica de Italia sobre las provincias del Imperio.

Es ahora que estalla de manera evidente la crisis que luego caracterizará casi todo el siglo III; una crisis en primer lugar demográfica, con graves repercusiones económicas, financieras, militares y sociales, que inevitablemente se convirtió en crisis politica. La disminución de la producción económica junto al crecimiento de las exigencias militares delante de la presión todavia más grave de los bárbaros ocasionó una espiral perversa de inflación-devalorización, la insubordinación todavia más grave del ejército y una creciente inestabilidad política, que vio el ejército como protagonista en la aclamación de los emperadores y vio a los emperadores obligados de buscar a toda costa su favor.

\footnotetext{
"Profesore di Historia Romana, Dipartimento di Scienze Storiche del Mondo Antica, Universiti di Pisa.
} 
En nuestra clase concentraré mi atención sobre algunos importantes aspectos del reinado de Septimio Severo (193-211 d. de C.), que resultarán útiles también para ilustrar la importancia, los carácteres y los criterios de utilización de las fuentes historiográficas antiguas y de las inscripciones, y además las ventajas y los límites del método prosopográfico (del greco prósopon, "máscara teatral, persona, personaje"), es decir del estudio de la historia familiar y personal de los protagonistas: condición social, parentela, uniones matrimoniales, carrera, amistades y vinculos politicos conectados con los cargos desempeñados.

Este método de estudio, elaborado por investigadores del siglo veinte como Friedrich Münzer, Edmund Groag y Ronald Syme, es particularmente fecundo en el estudio de la historia politica y de la sociedad romana, caracterizadas todavia por una estructura jerárquica y por relaciones de clientela, es decir de subordinación personal y familiar fundadas en obligaciones recíprocas. Pero éste no puede pretender ser la única clave de interpretación posible para todos los aspectos de la historia politica y los datos que nos ofrece no tienen que ser sobreinterpretados.

Antes de todo hablaré del pronunciamiento del 193 d. de C., que eliminó a Cómodo y llevó al poder a Pértinax, y propondré una confrontación entre la carrera de Pértinax y la de Septimio Severo antes de su subida al poder imperial, para comprender mejor la relación especial entre Severo y el ejército, en que estuvo fundada la fortuna de toda su dinastia. Eso nos permitirá también apreciar en una perspectiva metodológica la utilización de una epigrafe, un tipo de fuente absolutamente fundamental para las investigaciones prosopográficas.

Luego examinaré los criterios sobre los que Severo basó su relación con el ejército y la elección de sus generales, para ilustrar su estrategia politica. Examinaré también someramente a los otros emperadores de la dinastía y su relación con el ejército.

Pero en un primer momento hablaré de las fuentes griegas y latinas sobre las que está fundado nuestro conocimiento de esta época y de sus protagonistas (además de las inscripciones, las monedas y los hallazgos arqueológicos): Casio Dión, Herodiano, la Historia Augusta, Aurelio Víctor, Eutropio.

\section{CASIO DIÓN}

Casio Dión Cocceiano era originario de Nicea, actual Iznik ${ }^{1}$, una ciudad de Bitinia, en el Noroeste de la actual Turquia, que rivalizaba con la capital de la provincia, Nicomedia, y es conocida sobre todo por el famoso Concilio ecuménico del $325 \mathrm{~d}$. de C. que estableció la fórmula del credo católico. Su padre, Casio Aproniano, habia sido gobernador (proconsul) de la provincia senatorial de Lycia y Pamphylia, y luego gobernador (legatus Augusti pro praetone) de las provincias imperiales de Cilicia $(182-183 \text { d. de C. })^{2}$ y de Dalmacia $^{3}$. Por lo tanto su padre no era sólo un senador romano, sino que había sido también cónsul, y su familia era al mismo tiempo plenamente griega por lengua, cultura y sentimentos de identitad, y plenamente romana por lealtad politica y sentido de pertenencia a la elít senatorial y a su ideologia.

La fecha de su nacimiento es muy discutida. Ya que él afirma que fue testigo del primer discurso del emperador Cómodo en el senado en otoño del $180 \mathrm{~d}$. de C. ${ }^{4}$, se puede suponer que él acababa de recibir la toga viril y como hijo de senador tenía el privilegio de asistir a las sesiones del senado, según una antigua disposición de Augusto. Asi pues, Casio Dión habria nacido en el 165 o 166 d. de C.

Él mismo nos cuenta que estuvo con su padre en Cilicia en el $182-183^{5}$ y que era senador en Roma en los últimos años del reinado de Cómodo ${ }^{6}$. Evidentemente desempeñó la cuestura alrededor del $189 \mathrm{~d}$. de C., porque nos dice que en el 193 fue designado por Pértinax a la pretura ${ }^{7}$, que desempeñó en el 194.

En el 193, después de la muerte de Pértinax, escribió un "libro pequeño sobre los sucños y los prodigios que llevaron a Severo a esperar alcanzar el poder imperial", y esta obra, que Dión envió al mismo Severo, fue muy apreciada por él ${ }^{8}$.

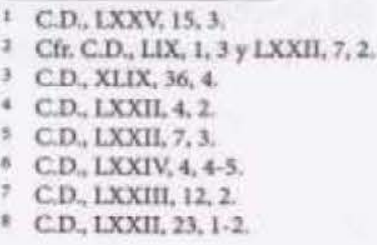

Revista de Histaria, ano 18, vols: 18-19, 2008-2009, Pp. 11-40. 
Sucesivamente Dión escribió otro libro pequeño "sobre las guerras y las revueltas estalladas después de la muerte de Cómodo", que él pudo presentar personalmente a Severo y luego incorporó en su obra histórica mayor ${ }^{9}$. Este particular nos permite decir que el contenido del segundo libro corresponde a las secciones de la Historia Romana de Dión favorables a Severo, que terminan con la victoria final sobre su rival Pescenio Nigro ( 31 de marzo del $194 \mathrm{~d}$. de C.). El libro, por lo tanto, no contenía ni la denominada primera Guerra Pártica (195) ni la sucesiva guerra civil de Septimio Severo contra Clodio Albino (197), y muy probablemente fue escrito en la primera mitad del 195.

Dión pudo presentarlo a Severo en Oriente, donde quizás se encontraba como gobernador de una provincia pretoria, como nos lleva a pensar un rescrito de Septimio Severo dirigido a un tal Dión conservado por el jurista Paulo en el Digesto 10 .

En este momento tenemos que ubicar la disgracia política de Casio Dión, cuya carrera se interrumpió bruscamente hasta el reinado de Macrino (217-218 d. de C.), cuando fue nombrado legado (legatus ad corrigendum statum civitatium) en Pérgamo y Esmirna, una especie de inspector y revisor de las cuentas de estas ciudades ${ }^{11}$.

Según algunos investigadores, como Fergus Millar, Dión fue regularmente cónsul bajo Septimio Severo y fue comes de Caracalla, es decir miembro del estado mayor del emperador durante su permanencia en Nicomedia (214-215 d. de C.). Pero esto no es probable, porque el cargo de legado en Pérgamo y Esmirna es un cargo de nivel simplemente pretorio, de que se puede argüir que en el 218 Dión no había aún desempeñado el consulado.

Su carrera así pues quedó bloqueada por más de veinte años, pero desde el 218 recibió una aceleración frenética. Según sus mismas palabras ${ }^{12}$, entre el 218 y el 229 Dión fue en primer lugar legado en Pérgamo y Esmirna, luego permaneció algùn tiempo enfermo en su ciudad nativa Nicea, desempeñó un cargo no mejor especificado "en África", fue sucesivamente gobernador (legatus Augusti pro praetore) de las provincias imperiales de Dalmacia y de Panonia Superior y finalmente, en enero del 229, fue cónsul por segunda vez, como cónsul ordinario y colega del emperador ${ }^{13}$.

Si es verdad que en el 218 era simplemente un ex pretor, el cargo "en África" tiene que ser la comandancia de la legión tercera Augusta en Numidia (y no el proconsulado de África), porque la Numidia era todavía considerada parte de la provincia de África, y entre este cargo y el gobierno de Dalmacia tenemos que suponer también un primer consulado, como cónsul sufecto (suffecti, es decir sustitutos, eran dichos los cónsules que no asumían el cargo al comienzo del año y por eso tenían mucho menos prestigio).

Por lo tanto podemos proponer esta cronologia:

- legado en Pérgamo y Esmirna en el 218-219 d. de C.;

- enfermo en Nicea en el 219;

- comandante de la tercera legión Augusta en Numidia en el 220-221;

- cónsul por primera vez, como cónsul sufecto, en el 222;

- gobernador (legatus Augusti pro praetore) de Dalmacia en el 222-223;

- gobernador (legatus Augusti pro praetore) de Panonia Superior desde el 223 al 228;

- cónsul por segunda vez, como cónsul ordinario, en el 229.

Este segundo consulado parecia el máximo del desquite por Dión, después de la humillación sufrida bajo Septimio Severo y Caracalla, pero marcó también el término definitivo de su carrera política.

$\mathrm{El}$ mismo historiador narra ${ }^{14}$ : "Ya que los pretorianos estaban muy irritados conmigo, el emperador tenía miedo que pudieran matarme, si me hubieran visto en el prestigio de aquel cargo (= el consulado), y me rogó pasar el tiempo de mi consulado fuera de Roma, en algún lugar de Italia».

Así Dión se refugió en su villa cerca de Capua, en Campania, y luego regresó definitivamente a Bitinia ${ }^{15}$; desde ahora no sabemos más nada de su vida.

CD, LXXII, 23,2,3

16 Dig. 50, $12,7$.

11 C.D., LXXIX, 7,4.

iz C.D., LXXX, $1,2-3$

15 C.D, LXXX, 2, 1.

if C.D. LXXX, 5, 1 .

is CD., LXXXX, 5, 1-2. 
Su obra mayor, una Historia Romana desde la fundación de la ciudad hasta su segundo consulado en el 229 d. de C., estaba compuesta de 80 libros, pero no está conservada integralmente: quedan sólo los libros 36-60 (con la narración de los años 68 a.C. -47 d.C.) y en forma fragmentaria los libros 78-79 (años 212-222 d. de C.). Además, tenemos la epitome (compendio) del monje bizantino Juan Xifilino (siglo XI) y algunos extractos; finalmente, la obra de Dión fue utilizada por Juan Zonara (siglo XII).

La fecha de composición de la obra de Dión es muy discutida. El testimonio fundamental es un pasaje donde el mismo historiador afirma ${ }^{16}$ : «Ya que esta obra [es decir el libro sobre las guerras civiles] le gustó mucho al mismo Severo, yo concebí el deseo de recoger todo lo que concierne a los Romanos...... Dión sigue diciendo que, por largo tiempo dubiteante, fue incitado por la Tyche (es decir la diosa Fortuna) a realizar su intención, y así concluye: «He recogido noticias sobre todos los acontecimientos desde los origenes de Roma hasta la muerte de Severo [es decir hasta el 4 de febrero del $211 \mathrm{~d}$. de C.] en diez años, y he escrito la narración de ellos en otros doce años. Los otros acontecimientos serán narrados a medida que avanzarán”.

Según algunos investigadores (Schwartz, Gabba, Millar en su libro de 1964), Dión empezó la recolección de noticias inmediatamente después de la publicación del libro sobre las guerras civiles; pero contra esta interpretación tiene valor la objeción de Glenn Bowersock: si asi fuera, esta fase preliminar de documentación sobre los acontecimientos hasta $211 \mathrm{~d}$. de C. habria ya terminado cinco o seis años antes del 211 , una cosa evidentemente imposible.

Otros especialistas (Reimarus, Vrind, el mismo Millar en un articulo de 2005) han supuesto que esta recolección de noticias hasta el $211 \mathrm{~d}$. de C. hubiera terminado precisamente en el 211, y por eso hubiera empezado en el 201.

En realidad, podemos decir solamente dos cosas: 1) el decenio de recolección empezó después de la publicación del libro sobre las guerras civiles, pero no inmediatamente después: la existencia de una larga pausa de titubeos es testimoniada por el mismo Dión y confirmada por la objeción de Bowersock que acabamos de ilustrar; 2) este decenio no puede haber empezado antes del 201, pero nada nos obliga de pensar que hubiera empezado en el mismo 201.

Lo que convenció a Dión de empezar su trabajo fue una intervención de la diosa Fortuna ${ }^{17}$. Normalmente, en el lenguaje de Dión, una intervención de la diosa Fortuna es un sueño ${ }^{18}$ : esta intervención especifica muy probablemente se puede identificar con el sueño que el historiador hubo en el mismo 211 , después de la muerte de Septimio Severo, pero antes de la muerte de Geta ${ }^{19}$; "Ya antes de que Caracalla quedara solo al poder [es decir, ya antes de la muerte de Geta, pasada el 19 o el 26 de diciembre del 211 d. de C.], me fue predicho por su padre que yo habria escrito también esto. En efecto, cuando ése [es decir, cuando Septimio Severo] habia ya muerto, me pareció ver en una grande llanura todo el ejército romano en pie de guerra, y en el mismo lugar, sobre un cerro, Severo sentado sobre una tribuna muy alta hablando a los soldados. Y al verme alli me dijo: "Aproximate, Dión, para que pueda conocer cuidadosamente y después pueda escribir todo lo que está dicho y hecho"».

Este sueño no es una exhortación de proseguir más allá del 211 una narración ya empezada, porque el término que Dión se propuso no fue jamás el 211 , sino lo que le hubiera concedido la diosa TycheFortuna ${ }^{20}$. El sueño del 211 es simplemente una exhortación de empezar el trabajo; por eso, si la recolección de noticias llegaba hasta el 211, eso es porque solamente en el 211 Dión empezó su trabajo, es decir solamente desde el 211 él registró los acontecimientos a medida que pasaban, y por lo tanto necesitaba de investigaciones retrospectivas únicamente de los acontecimientos anteriores.

Podemos asi pues concluir que Dión recogió noticias acerca de los acontecimientos hasta el $211 \mathrm{~d}$. de C. en los diez años desde el 212 hasta el 222 y escribió su obra mayor desde el 222 hasta el 234; de manera análoga T.D. Barnes en 1984 propuso los años $211-220$ por la recolección de noticias, y 220-231 por la redacción.

La atmosfera política en la cual el historiador escribió su Historia Romana fue por lo tanto la del reinado de Severo Alejandro (222-235 d. de C.), y no la de Septimio Severo (193-211) y Caracalla (211-217), como afirma al contrario Fergus Millar.

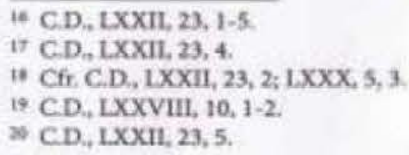

Revista de Historia, año 18, vols. 18-19, 2008-2009, pp. 11-40. 
Según el mismo Dión, su obra era dividida en tres partes: la primera (libros I-LI) con la narración de los acontecimientos desde los origenes hasta el reinado de Augusto; la segunda (libros LII-LXXII) desde Augusto hasta Marco Aurelio; la tercera (libros LXXIII-LXXX) desde Cómodo hasta el 229 d. de C. Esta última parte es quizás la más interesante, porque no es una compilación de obras anteriores, sino que está fundada sobre el testimonio de un contemporáneo, introducido en el entorno del poder y experto de política, administración, derecho y problemas militares.

La estructura es analistica, pero con un esfuerzo para aproximarse a la mayor complejidad de la historia monográfica, que a veces provoca una cierta confusión cronológica. Dión tiene la veleidad de formular teorias historiográficas generales y profesa una especie de culto de la denominada "dignidad de la historia" (ónkos tes historias): por eso omite como indignos de la grande historia muchos detalles esenciales, nombres, números, fechas, indicaciones geográficas ${ }^{21}$. En su tentativa de aspirar a lo esencial, a la imitación del grande historiador griego Tucídides y del latino Salustio, a menudo Dión se vuelve esquemático, equivocando lo esencial y lo superfluo. Solamente en la sección contemporánea logra superar estos limites, porque advierte la obligación y la responsabilidad de testificar a la posteridad lo que ha visto y aprendido: así él, aunque disculpándose con el lector, narra también detalles que no considera dignos de la grande historia...22.

Su modelo por la lengua, el pensamiento y la utilización de discursos ficticios es constantemente Tucidides, como notaba ya el escritor bizantino Focio ${ }^{23}$. Sus fuentes son muchas y varias, también latinas, pero no es fácil determinarlas. En general parece que él prefiera grandes sintesis analísticas, incluso Livio (desde el libro 36).

Desde luego utilizó también las memorias escritas por algunos emperadores, Augusto ${ }^{24}$, Adriano ${ }^{25}$, Septimio Severo 26 . Se puede demostrar también una utilización sistemática de documentos de archivo, en primer lugar las actas del senado, ya sea para épocas lejanas, por lo menos desde César, que empezó la registración sistemática de las actas del senado, ya sea para la época contemporánea. Particularmente significativos por el pasado más lejano son los pasajes donde Dión cita algunas deliberaciones del senado ( senatus consulta) sin notar que no fueron actuadas jamás, o fueron actuadas sólo parcialmente, evidentemente porque él sacó la noticia del archivo del senado y no de obras de historiadores anteriores, contemporáneos de los acontecimientos.

Por ejemplo Casio Dión afirma que la colonia de Lugdumum (actual Lyon) fue fundada en 43 a. de C. por Munacio Planco y Emilio Lépido, según el orden del senado ${ }^{27}$, pero es cierto que en su fundación Lépido no participó: evidentemente en el archivo del senado Dión encontró sólo la deliberación que mandaba la fundación de la colonia, pero no la relación sobre la ejecución de este orden, donde desde luego se hablaba sólo de Munacio Planco.

Para la época contemporánea son muy interesantes también las citas literales de epistolas imperiales leídas en el senado cuando Dión se encontraba sin falta en otro lugar, y por lo tanto conocidas por él sólo a consecuencia de sus investigaciones sucesivas en el archivo del senado.

A veces Dión utiliza también algunas fuentes epigráficas, pero sin conducir investigaciones sistemáticas: generalmente explota su conocimiento de los lugares donde estaban expuestas (Roma, donde vivió muchos años; Bitinia, que era su patria; Asia, donde desempeñó el cargo de legado en Pérgamo y Esmirna; la ciudad italiana de Ariminum, actual Rimini, donde probabilmente estuvo de paso en su viaje hacia Panonia; quizás también Accio, cerca de la actual ciudad griega de Prévesa, famosa por la victoria naval de Octaviano contra Cleopatra).

Frecuentemente el historiador agrega en la narración un discurso ficticio de un protagonista, o un debate entre dos personajes; eran composiciones autónomas, concebidas para ser leídas en salones literarios (recitationes) y a menudo expresaban las ideas politicas del autor. Asi en el libro LII el debate entre Agripa y Mecenas sobre la disposición monárquica o republicana del estado romano refleja los problemas de la edad de Severo Alejandro, cuando Dión escribia, más bien que los de la edad de Augusto, a la cual se refiere.

1 Cfr. C.D., XXXVII, 7,6 - 8, 1; XIII, 19, 3-4; XIIV, 14, 3; XIVI, 35, 1; XIVII, 10, 1; XIVII, 13, 1.

$n$ C. D., LXXII, 18, 3:4.

3 Foc, Bibl. 71 .

34 C.D., XIIX, 35, 3

25 C.D. LXVI, 17, 1; LXIX. 11, 2

is C.D. LXXV, 7, 3.

a) C.D., XIV, 50, 2,3. 
La obra de Dión fue utilizada por el historiador griego Herodiano ya cerca de la mitad del siglo III d. de C., por el anónimo autor de la Historia Augusta entre el IV y el V siglo, y por muchos autores bizantinos hasta el siglo XII.

\section{HERODLANO}

Del origen y de la vida del historiador griego Herodiano no conocemos prácticamente nada. Desde luego no puede identificarse ni con el senador Tiberio Claudio Herodiano, atestiguado como ayudante (legatus) del gobernador (proconsul) de Sicilia en la época severiana, ni con el gramático Herodiano Técnico, autor de una obra de prosodia dedicada a Marco Aurelio.

Lo que él mismo afirma nos permite solamente decir dos cosas muy generales:

1) el historiador Herodiano vivió en la época narrada en su obra (180-238 d. de C.): «He recogido fielmente en mi narración acontecimientos históricos que no he aprendido de otros y no son desconocidos, ni sin testigos, sino son todavia presentes en la memoria de los lectores $)^{28}$;

2) él desempeñó funciones no mejor definidas al servicio del emperador y del estado ${ }^{29}$. No es claro si tenemos que pensar a cargos en el palacio imperial o en el servicio administrativo del emperador, o del emperador y de las autoridades de la ciudad, y por eso no sabemos ni siquiera si Herodiano era un liberto o un caballero.

No conocemos su origen, que ha sido supuesto en Alexandria (como su homónimo gramático), Siria o Asia menor, pero sin fundamento sólido.

Su obra histórica, titulada "Historia imperial después de Marco", es dividida en ocho libros y narra los acontecimientos desde el 180 hasta el $238 \mathrm{~d}$. de C., es decir desde la subida al trono de Cómodo hasta la de Gordiano III. Muy probablemente no fue publicada bajo el mismo Gordiano, dado que en ella hay severas críticas contra los príncipes demasiado jóvenes (como Gordiano III, emperador a la edad de trece años), contra Gordiano I y los sostenedores de Gordiano III. Quizás fue publicada bajo Filipo el Árabe (244-249 d. de C.), como pensa Filippo Cássola, o bajo Decio (249-251), como prefiere pensar Géza Alföldy.

Durante el siglo veinte Herodiano ha sido objeto de revalorización, sobre todo de parte de Cássola y Fulvio Grosso, pero también de juicios muy severos (Hohl, Alföldy, Kolb). Recientemente Martin Zimmermann y Henry Sidebottom han subrayado la ligazón de Herodiano con la denominada Segunda Sofística, un florecimiento literario del mundo griego en la edad imperial romana fundado sobre todo en la retórica.

Algunos limites y defectos de su obra son evidentes: imprecisión, generalidad, superficialidad, retórica; pero, según Cássola, no hay falsificación intencional y el testimonio de Herodiano continúa siendo importante porque él es un testigo directo, que sólo ocasionalmente completó sus informaciones con fuentes escritas.

Según Alfóldy y Kolb, al contrario, Herodiano utilizó a Casio Dión hasta que fue disponible, y lo manipuló sin escrúpulos para construir una verdadera novela histórica. Según Alföldy, el esquema básico es una serie de medallones (en alemán Einzelbilder, "retratos aislados"), con una fuerte polarización entre el héroe del momento y su antagonista, y una estructura dramática caracterizada por la composición circular (Ringkomposition): una introducción que hace subir la tensión; un ápice dramático-retórico; un final conmovedor. Falta casi completamente el cuadro geográfico y cronológico, porque no le interesa al autor y porque asi es más facil hacer transposiciones de un contexto a otro con finalidades dramáticas.

En realidad, ésta es una visión demasiado esquemática y negativa; Herodiano tiene que ser encuadrado más bien en la Segunda Sofistica: su obra quiere ser una reflexión moral sobre la historia y la naturaleza del hombre; no hay falsificación intencional, sino subordinación de la narración a este objetivo especifico.

Respecto a Casio Dión, Herodiano tiene un sentido más vivo de la crisis del imperio (Krisenempfindung), como ha mostrado muy bien Alfoldy.

Aunque Herodiano también, como Casio Dión, tenga una posición política sustancialmente favorable al senado, con simpatia hacia las clases acomodadas, él percibe más claramente la decadencia de la vieja nobleza: por él Clodio Albino es noble, pero venido a menos, mientras Pértínax es el mejor, aunque sea un "hombre nuevo" (homo novus); Casio Dión también es muy favorable a Pértinax, pero precisamente por eso no insiste sobre su origen, como al contrario lo hace Herodiano.

2 How $1,2,3$.

27 Hos, 1, 2, 5: en basilikatis e demosiats hypereniais, que corresponde probablemente al latino in Caesareis et publicis officias).

Revista de Historia, año 18, vols. 18-19, 2008-2009, pp. 11-40. 
El autor de la "Historia imperial después de Marco" nota las novedades principales de su tiempo, el ascenso de las provincias, el papel decisivo de las legiones del Danubio, la amenaza mortal al confin norte del imperio, todavia subestimada por Casio Dión, preocupado sobre todo del confín oriental.

Herodiano acentúa ulteriormente la contraposición, ya presente en Casio Dión, entre la libertad, personificada por Marco Aurelio, y la tiranía de los emperadores sucesivos, y ve a un emperador soldado (Soldatenkaiser) ya en Septimio Severo.

\section{LA HISTORIA AUGÚSTEA}

Con el título de Historia Auguistea (en latino Historia Augusta), "historia imperial" o "historia de los emperadores", está indicada una colección de treinta biografias de emperadores, desde el ascenso al trono de Adriano en el $117 \mathrm{~d}$. de C. hasta el de Diocleciano en el 284.

En realidad este título es moderno, ya que fue utilizado por primera vez por Isaac Casaubon en su edición publicada en París en 1603; el grande humanista francés lo sacó de un pasaje de la biografia del emperador Tácito, donde el historiador homónimo es definido scriptor historiae Augustae, escritor de historia imperial ${ }^{30}$.

Los manuscritos nos ofrecen un titulo sensiblemente diferente: Vitae diversoram principum et tyrannoram, es decir "Vidas de diferentes principes y usurpadores desde el divino Adriano (117-138 d. de C.) hasta Numeriano (283-284 d. de C.) escritas por diferentes autores".

Habrian sido escritas por seis diferentes autores, algunas bajo Diocleciano (284-305 d. de C.), otras bajo Constantino (306-337 d. de C.). Cuatro autores afirman haber escrito bajo Diocleciano: Elio Sparciano, Julio Capitolino, Vulcacio Galicano y Elio Lampridio. Dos serian de la edad de Constantino: Trebelio Polión y Flavio Vopisco, el único que declara su origen, precisamente la ciudad siciliana de Siracusa.

La colección contiene biografias de Augusti (emperadores), Caesares (herederos legitimamente designados), y tyranni (usurpadores), y tienen un largo muy variable: sólo siete capitulos son dedicados a Elio Vero (el heredero originario de Adriano, fallecido antes de él), 68 capitulos a Severo Alejandro (222-235 d. de C.).

Desde los Maximini duo (dos Maximinos) hay también biografias colectivas de dos o más personajes; Gondiani tres (238-244 d.C.), Maximus et Balbimus ( 238 d. de C.), y después de una laguna correspondiente a los reinados de Filipo el Árabe (244-249 d. de C.), Decio (249-251), Treboniano Galo (251-253) y Emiliano (253), aún Valeriani duo (253-260), Gallieni duo (253-268), Tyranni triginta, es decir los usurpadores desde el 260 hasta el $275 \mathrm{~d}$. de $\mathrm{C}_{\text {, }}$, incluso los del imperium Galliarum (imperio separatista de las Galias) y del reino oriental de Palmira, Quadrigae tynannorum ("cuarteto de usurpadores", es decir Firmo, Saturnino, Próculo y Bonoso, 272 280 d. de C.), y finalmente Carus, Carinus et Numerianus (282-285 d. de C.), hasta el ascenso al poder de Diocleciano.

Existe la fundada sospecha de que los nombres de los seis autores sean ficticios. Algunos habrian escrito biografias no continuas de emperadores del segundo y del tercero siglo; algunas atribuciones son contradictorias: por ejemplo, la vida de Pescenio Nigro, rival de Septimio Severo, seria obra de Elio Sparciano y la de Clodio Albino seria obra de Julio Capitolino, pero en ambas se afirma que son obras del mismo autor.

El modelo declarado es Suetonio, escritor de la edad de Adriano autor de biografias de los primeros doce emperadores, valorizado como campeón del género biográfico contrapuesto al histórico, como es dicho en la Vida de Probo por el pretendido Flavio Vopisco: "Eñ la narración de la vida y del tiempo de los emperadores, mi intención es imitar no a los Salustios, los Livios, los Tácitos, los Trogos y a todos los autores elegantes, sino a Mario Máximo, Suetonio Tranquilo, Fabio Marcelino, Gargilio Marcial, Julio Capitolino, Elio Lampridio y a los otros que han transmitido el recuerdo de estos acontecimientos no con elegancia, sino más bien con verdad ${ }^{31}$.

En efecto las noticias son organizadas por argumentos (per species): los antepasados y la familia; el nacimiento, los nombres y los apodos; los presagios de la subida al poder (omina imperii); el carácter; la vida antes de la subida al poder; los acontecimientos del reinado (guerras, legislación, obras públicas); la fecha y las circunstancias de la muerte; los presagios de la muerte (omina mortis); el retrato físico; los honores eventuales después de la muerte. Este esquema fundamental puede sufrir variaciones en el orden de los temas, omisiones, añadiduras, o el desarrollo ipertrófico de una sección particular, como la de los vicios de Heliogábalo 32 .

\footnotetext{
3) HA, Tac, 10,3.

31 HA, Prog, 27.

32 HA. Heliog. 18-23.
} 
Hay por lo tanto una preponderancia absoluta de los elementos biográficos y anecdóticos en comparación con los propiamente historiográficos, ya sea por la observancia de las leyes del género literario, ya sea por una elección de gusto. Así el interés de Suetonio por la vida privada degenera en complacencia hacia las noticias frivolas, obscenas y escandalosas, sobre todo con referencia a emperadores considerados malos, como Lucio Vero, Cómodo o Heliogábalo, más o menos al nivel de la prensa escandalista de hoy dia.

Una degeneración de un carácter suetoniano es también la utilización abusiva de documentos, porque, mientras los citados por Suetonio, responsable de los archivos imperiales, son documentos auténticos, los citados a menudo por la Historia Augusta son casi siempre falsos.

Ellos son nada menos que 158: 68 letras, 60 oraciones, 20 decretos y aclamaciones del senado (senatus consulta y adclamationes), 10 epigrafes. El engaño queda manifiesto por su distribución desigual al interior de la obra, ya que son más numerosos con referencia a personajes poco conocidos, y por muchos anacronismos que contienen en lo que se refiere a la lengua, al estilo, al formulario, a las instituciones.

Esta exasperación de carácteres suetonianos (con preponderancia de la vida privada y obsesión por los documentos) muy probablemente fue sugerida también por el ejemplo de Mario Máximo, que fue cónsul por segunda vez en el 223 d. de C. y, a continuación y según el modelo de los doce Césares suetonianos, escribió las biografias de doce emperadores desde Nerva hasta Heliogábalo (96-222 d. de C.).

Este autor es citado 30 veces por la Historia Augusta con referencia a documentos o a chismes (anécdotas, habladurias escandalosas, detalles obscenos) y precede al mismo Suetonio en la lista de los modelos citados en el pasaje de la vida de Probo que ya hemos leído. También Amiano Marcelino, historiador del IV siglo, confirma la propensión de Mario Máximo por los escándalos ${ }^{33}$.

En la Historia Augusta es constante una actitud tradicionalista, favorable a la nobleza senatorial y hostil a los parvenus (homines novi) y al poder excesivo del ejército. Por eso en su juicio los emperadores mejores son Severo Alejandro (222-235 d. de C.) y Probo (276-282 d. de C.), que representan el ápice de la influencia senatorial durante el siglo tercero, mientras el peor es Galieno (253-268 d. de C.), culpable de la exclusión de los senadores de los comandos militares.

Así la biografía de Severo Alejandro se transforma en un panegírico, donde Alejandro es contrapuesto como un modelo de "santo pagano" al monstruo Heliogábalo, ápice de toda depravación.

Este tradicionalismo presenta a veces matices nacionalistas y antibarbáricas (como en la vida de Carino 9, 3 a propósito de los Persas), y también de defensa del paganismo tradicional y de aversión contra los cultos extranjeros.

Con referencia a las fuentes utilizadas, desde hace tiempo se ha reconocido una sección "buena" que contiene las biografias desde Adriano hasta Geta, pero al interior de esa tenemos que distinguir algunas vidas dichas "principales" (Hauptviten por los alemanos), que utilizan materiales de buena calidad (Adriano, Antonino Pío, Marco Aurelio, Cómodo, Pértinax, Didio Juliano, Septimio Severo y Caracalla), y algunas vidas "secundarias" (en alemán Nebenviten) mucho menos confiables, porque son construidas con materiales sacados de las vidas principales, enriquecidos con noticias inventadas y documentos fícticios (Elio César, Avidio Casio, Pescenio Nigro, Clodio Albino y Geta).

Las vidas "principales" presuponen la utilización de una fuente muy buena; en efecto muchas noticias individuales han sido confirmadas por otras fuentes, o por epigrafes y monedas. Sin embargo la naturaleza de esta fuente es muy discutida. Se ha supuesto una fuente de tipo analistico que continuaria la narración de Tácito ("el último grande historiador de Roma", según la definición de Domaszewski), o bien la combinación de una fuente analística y de una biográfica (Heer, Schwendemann). Pero ahora ya se prefiere pensar a una fuente única, de tipo biográfico, sobre cuya identificación no hay acuerdo: a menudo ésta ha sido identificada con el mismo Mario Máximo (Hohl, Birley, Johne), o bien con un autor desconocido (Ignotus, "the good biographer"), que de vez en cuando habria sido enriquecido con Mario Máximo, pero sólo por curiosidades y detalles escandalosos (Barbieri, Syme, Barnes).

Las vidas "secundarias" (Nebenviten) de esta primera sección reelaboran noticias de las vidas "principales", con una acentuada estructuración retórica que incluye proemios y epilogos, con muchas citas sospechas de versos, nombres, genealogias, documentos, y descripciones ciertamente de fantasia con referencia al aspecto físico, al carácter, a los costumbres: descripciones particularmente sospechosas cuando atañen a personajes que sufrieron la damnatio memoriae, es decir la abolición del recuerdo, con la destrucción de todos los retratos y las estatuas.

\footnotetext{
39. Asem., XXVIII. 4, 14.

Revista de Historia, afio 18, vols. 18-19, 2008-2009, pp. 11-40.
} 
La segunda sección de esta recolección de biografias imperiales es claramente peor. Contiene algunas citas de Herodiano y de Dexipo, autor de una crónica en 12 libros hasta el $268 \mathrm{~d}$. de C. Es posible también una utilización de Casio Dión, directa o bien por el trámite de Herodiano (Kolb). Algunas consonancias con el Liber de Caesaribus (el "libro de los emperadores") de Aurelio Víctor, sobre los emperadores desde Augusto hasta Constancio II ( $361 \mathrm{~d}$. de C.), y con el Breviarium ab urbe condita ("Compendio histórico desde la fundación de Roma") de Eutropio, desde Rómulo hasta el 364 d. đe C., sugieren que la Historia Augusta haya utilizado también una de estas obras o bien su supuesta fuente común, la denominada "Historia imperial de Enmann" (Enmann's Kaisergeschichte), asi llamada del nombre del especialista alemán Alexander Enmann.

Muchos nombres de historiadores citados por la Historia Augusta aparecen ficticios: Asclepiodoto, Julio Eteriano, Dagelio Fusco, Túrdulo Galicano, Acolio etcétera.

Por lo tanto, cada noticia de la Historia Augusta tiene que ser cuidadosamente averiguada, pero no puede ser rechazada a priori.

El estilo es simple y periodistico, según las palabras de Momigliano; su lengua es tardia, con formas y construcciones coloquiales y muchos términos raros o técnicos.

Delante de tantos elementos sospechos (noticias y documentos falsos, fuentes ficticias, anacronismos), hay que dudar también de la paternidad y de la datación declarada de la obra.

Por primera vez, en un memorable ensayo de 1889 , Hermann Dessau sostuvo que la Historia Augusta fuese la obra de un autor único de la época del emperador Teodosio I ( $379-395 \mathrm{~d}$. de C.); probarian este aserto las incongruencias y contradicciones ya recordadas, muchos anacronismos, y particularmente la presencia de nombres y términos técnicos característicos del IV siglo tardio, y finalmente los pasajes que parecen derivados de autores del mismo siglo, como Aurelio Victor, Eutropio o la "Historia imperial de Enmann".

Su hipótesis fue rechazada por algunos autores como Mommsen, Peter, De Sanctis, Lécrivain y Momigliano, pero generalmente fue recibida y desarrollada. Otto Seeck (1890 y 1894) reconoció algunas alusiones al emperador Honorio y propuso una fecha en torno del $407 \mathrm{~d}$. de C. Alfred von Domaszewski (1916-1920) creyó reconocer a un autor oriundo de Nemausus (actual Nimes en la Galia meridional), que escriberia nada menos que a fines del siglo VI d. de C.

Norman Baynes (1926) supuso que el anónimo autor fuera un contemporáneo y un sostenedor del emperador Juliano el apóstata ( $362-363 \mathrm{~d}$. de C.), mientras Henri Stern (1952) preferia pensar al 353, bajo Constancio II. Werner Hartke (1940) propuso como autor a Nicómaco Flaviano el joven, prefecto de la ciudad bajo el usurpador Eugenio, derrotado por Teodosio. András Alföldi y Joseph Straub vieron en la Historia Augusta una especie de "Historia contra los cristianos", en respuesta a la "Historia contra los paganos" del historiador cristiano Orosio, publicada en el $417 \mathrm{~d}$. de C.

Hoy dia prevalece la tesis de un autor único, con una fecha de composición que oscila entre el reinado de Teodosio I (Schwartz, Syme) y lo de Honorio (Chastagnol, Schmid, Johne, Straub, Mazzarino), es decir entre el 392 y el 423. Solamente Adolf Lippold $(1990,1998)$ ha representado la fecha tradicional.

Al contrario, no hay acuerdo sobre la pretendida presencia en la obra de una finalidad tendenciosa de tipo ideológico (Tendenz en alemán). Se ha supuesto ya una apologia del emperador Juliano el apóstata (Baynes), ya una polémica contra la sucesión heredera, que habría como blanco los sucesores de Teodosio (Hartke), ya una polémica anticristiana para solicitar una política de tolerancia hacia los paganos de parte de los emperadores cristianos (Straub).

En realidad, los pasajes que podrian justificar estas hipótesis son pocos y escasamente significativos. Por eso Ronald Syme excluye la presencia de una cualquiera Tendenz y explica la decisión del autor de esconderse detrás de nombres ficticios como un juego o divertissement erudito que nacería de su sense of humour y de su gusto parodístico más bien que de un deseo de polémica ideológica. El autor sería un grammaticus cuyo público era la aristocracia romana del siglo IV tardio, preponderantemente pagana y nostálgica, pero codiciosa sobre todo de curiosidades eruditas y obscenas, como afirma polémicamente Amiano Marcelino ${ }^{34}$. Si hay una polémica en la Historia Augusta, ésta es propiamente contra el modelo tacitiano de historia defendido por Amiano Marcelino, pagano como el autor de la Historia Augusta, al cual se le contrapone, como hemos ya dicho, un modelo suetoniano de biografia anecdótica, erudita y chismosa.

La invención prevalece de un modo todavía más claro: a medida que la narraciốn avanza, el autor se vuelve todavia más audaz y libre, y crea asi una historia novelesca (mythistoria) por el puro gusto del engaño. No hace falta subrayar la dificultad extrema que una fuente con estas caracteristicas presenta para el historiador

\footnotetext{
34 Aмm, XXVIII, 4, 14 .
} 
moderno que quiera utilizarla en su investigación.

\section{SINTESIS DEL PERÍODO 193-211 D. DE C.}

Antes de examinar los problemas que hemos preanunciado (el pronunciamiento de 193 d.C., las carreras de Pértinax y de Septimio Severo, la elección de los generales y la estrategia politica de Severo), deseo resumir los acontecimientos fundamentales del periodo desde la muerte de Cómodo hasta la de Severo.

La noche entre el 31 de diciembre del 192 y el dia del año del 193 el emperador Cómodo fue asesinado y reemplazado por el prefecto de la ciudad, Publio Helvio Pértinax. Pero después de sólo 87 días, el 28 de marzo del 193, Pértinax fue asesinado por los pretorianos.

En la disputa que se desencadenó, el senador Didio Juliano, con la promesa de otorgar 25.000 sestercios a cada pretoriano, pudo prevalecer sobre el rival Flavio Sulpiciano, prefecto de la ciudad y suegro de su antecesor Pértinax, que ofreció sólo 20.000 sestercios.

Pero ya el 9 de abril, sólo 12 dias después de la muerte de Pértinax, las tropas de Panonia Superior aclamaron al gobernador Septimio Severo, y algunos dias después también las legiones de Siria aclamaron a un nuevo emperador, el gobernador Pescenio Nigro, que ya el 30 de mayo fue reconocido emperador por Egipto.

Antes de todo movimiento, Severo se aseguró el apoyo del gobernador de Bretaña, Décimo Clodio Albino, otorgándole el título de César, es decir heredero designado. Luego se puso en marcha hacia Roma, con una armada compuesta de destacamentos (vexillationes) de sus legiones bajo la comandancia de los generales Leto y Valeriano.

Abandonado por sus sostenedores, Didio Juliano fue asesinado el 1 de junio, y Severo ingresó a Roma el 10 de junio. Aquí él licenció las cohortes pretorias que habian eliminado a tres emperadores en el espacio de cinco meses y formó nuevas cohortes con efectivos dobles reclutando en ellas a soldados de sus legiones panónicas.

Muy probablemente en aquel entonces Severo decidió practicar una drástica devaluación del denario, rebajándo hasta $47,5 \%$ el porcentaje de plata. Además, Severo celebró solemnemente la apoteosis (consecratio) de Pértinax, que fue también la ocasión de una dádiva de dinero al pueblo de Roma (congiarium) y de espectáculos grandiosos (ludi).

Después de sólo 30 días marchó de nuevo hacia la guerra contra Nigro, para la cual habia sido precedido por la armada de su general Tiberio Claudio Claudiano.

Mientras Severo quedaba en Perinto, capital de la provincia de Tracia, en la costa curopea de la Propóntide (actual Mar de Mármara), Claudio Claudiano vencía en su nombre cerca de Cizico (diciembre del $193 \mathrm{~d}$. de C.) y de Nicea (comienzo de enero de 194 d. de C.).

La batalla final fue vencida por el general severiano Publio Cornelio Anulino el 31 de marzo del 194 cerca de Isso, actual Alessandretta, el mismo lugar de una célebre victoria de Alejandro sobre el rey persa Dario, y Pescenio Nigro fue matado mientras intentaba de escaparse entre los Partos. La expedición proseguió a la otra parte del río Éufrate con la denominada primera guerra pártica, en la primavera del 195, contra los Osroenos y los Árabes Scenites de la Mesopotamia septentrional y los Adiabenos alrededor de Arbela, más allá del rio Tigris, otro lugar conectado con la memoria de Alejandro: estas poblaciones eran todas acusadas de haber ofrecido su ayuda a Nigro y de haber ocupado algunas fortalezas romanas de Mesopotamia. Así nació la nueva provincia de Osroene, alrededor de Nisibis, que estaba formada por territorios sustraídos al rey aliado Abgar de Edesa, castigado por su apoyo a Nigro.

Ya en el verano del 195 Severo se proclamó hijo del divino Marco Aurelio, que lo habria adoptado a punto de muerte: de esta manera Severo se transformaba en emperador legitimo y heredero de todos los bienes de los Antoninos. Al mismo tiempo su mujer Julia Domna recibió el título de "madre de los cuarteles" (o "de las casernas"), es decir de los soldados (mater castrorum), el titulo que habia sido creado para Faustina menor, la mujer de Marco Aurelio, y su hijo primogénito Septimio Bassiano, mejor conocido con el apodo de Caracalla, recibió el nuevo nombre de Marco Aurelio Antonino y el título de César, que lo señalaba como heredero designado. Entonces él era un niño de siete años.

Esta decisión de Severo, que prácticamente hacia ineficaz el título de César ya otorgado a Clodio Albino, indujó a éste último a proclamarse Augusto y a rebelarse. Así Severo pudo acusarlo de ingratitud, 
traición y perjuro, y el 15 de diciembre del 195 el senado declaró a Albino enemigo público del pueblo romano.

Después de una etapa en Roma (196 d. de C.), Severo alcanzó a Albino y lo venció cerca de Lyón (Lugdunum) el 19 de febrero de 197 d. de C.; Albino se suicidó y la ciudad fue saqueada. Se siguió una represión feroz, con ejecuciones capitales y confiscaciones: la Historia Augusta nos transmite una lista de 25 senadores asesinados ${ }^{35}$, que parece sustancialmente fidedigna.

Mientras tanto los Partos habian invadido la provincia recién constituida de Osroene, aunque la capital Nísibis, defendida por el general Julio Leto, hubiese resistido al asedio. Estalló así la denominada Segunda Guerra Pártica, esta vez contra los propios Partos. El 28 de enero del 198 Severo ingresó triunfalmente en la capital pártica Ctesifonte, en el centésimo aniversario del ascenso de Trajano al imperio (98 d, de C,), y 82 años después del ingreso de Trajano vencedor en la misma ciudad (116 d. de C.).

En esta ocasión Caracalla, todavia un niño de menos de diez años, fue proclamado Augusto y asociado formalmente al poder de su padre, mientras su hermano Geta recibió el título de César.

Mesopotamia se volvió provincia bajo un prefecto de rango ecuestre y recibió una guarnición formada por dos nuevas legiones. Después de dos tentativos fracasados de expugnar Hatra, una ciudad caravanera colocada en el desierto de la Mesopotamia septentrional, Severo pasó una temporada de algunos meses en la provincia de Siria (198-199 d. de C.), que dividió en dos provincias menores (Syria Coele y Syria Phoenice). Luego se trasladó a Egipto (199-200 d. de C.), donde autorizó la ciudad de Alexandria a instituir un senado local (bulé), solicitado en vano por los Alexandrinos desde la época de Augusto, y mandó que el sepulcro de Alejandro fuese sellado, para proclamar simbólicamente que ninguno, excepto el mismo emperador, podia participar en su carisma.

Después de otra permanencia en Siria, Severo regresó en elRoma en 202, a través de Asia y de las provincias danubianas.

El 9 de abril del 202 celebró el decenal de su ascenso al poder, y conjuntamente su victoria pártica y el matrimonio de su hijo mayor Caracala con Plautila, la hija del prefecto del pretorio Fulvio Plauciano, conciudadano y pariente de Severo. En esta ocasión el emperador repartió 10 monedas de oro (es decir 250 denarios o bien 1000 sestercios) a cada uno de los 200.000 hombres de la plebe de Roma inseritos en la lista de los que habian derecho a las distribuciones gratuitas de trigo (plebs frumentaria).

En el 202-203 visitó la provincia de África, donde se conducian operaciones militares a lo largo del confin sur hacia los nómadas del desierto. Según el escritor cristiano Tertuliano, Severo defendió a algunos senadores cristianos acusados injustamente; de todos modos al tiempo de su presencía en África se remonta el martirio de Perpetua y Felicidad en Cartago ( 7 de abril del 203). En su ciudad de origen Leptis Magna, a la cual le concedió también el derecho itálico, es decir exenciones físcales y otros privilegios, Severo realizó un programa de grandes obras públicas, mientras muchas otras ciudades fueron promovidas a la condición de municipios.

En el 204 Severo celebró en Roma con extraordinaria solemnidad las séptimas fiestas seculares (ludi saeculares), que según una tradición etrusca muy antigua, se celebraban cada 110 años. Pero mientras tanto caía la estrella de Fulvio Plauciano, prefecto del pretorio sin colegas por lo menos desde el $200 \mathrm{~d}$. de C. El 22 de enero del 205 Plauciano fue asesinado por su yerno Caracala y sus inmensos bienes fueron confiscados.

En los primeros meses del 208 Severo se marchó hacia Bretana, donde ya en el 207 Lucio Alfeno Seneción habia conducido operaciones militares contra las poblaciones del Norte, los Caledones de Escocia actual. Es muy probable que el proyecto previera la conquista total de la isla, como atestigua la grande base militar de Carpow, pero las dos campañas del 209 y 210 no fucron resolutivas, y la tercera fue impedida por la muerte de Severo.

Ya hacia la fin del 209 también Geta recibió el título de Augusto: en efecto se le llama Augusto ya en un diploma militar (es decir un certificado de licenciamiento de un soldado) con la fecha del 7 de enero del 210. Por primera vez en su historia el imperio estaba bajo tres emperadores en el mismo tiempo, porque asi Septimio Severo esperaba evitar contiendas entre sus hijos.

EI 4 de febrero de 211 Severo murió en Eburacum (actual York) y su proyecto de conquista total de Bretaña fue abandonado. Pero el "condominio" de Caracala y Geta en el poder imperial duró solamente pocos meses: ya el 19 o el 26 de díciembre del 211 Geta fue asesinado y Caracala quedó solo al poder.

3 HA, Sev, 13.

Revista de Historia, año 18, vols. 18-19, 2008-2009, pp. 11-40. 


\section{EL PRONUNCIAMIENTO CONTRA CÓMODO DEL 193 D. DE C.}

Según lo que hemos preanunciado, ahora examinaremos el pronunciamiento, o golpe de estado, del 193 d.C. que le dio el poder a Pértinax y confrontaremos las carreras de Pértinax y de Septimio Severo para comprender mejor sus relaciones con el ejército. En efecto esta es la clave de comprensión de todo, la base sobre que Severo construyó su poder y el de su familia; la dinastía fundada por él duró hasta que resistieron estas relaciones privilegiadas, nada menos que 43 años, a pesar de muchos errores de sus sucesores. Ninguno de ellos logró mantener el carisma de Severo; Caracalla fracasó en sus veleidades de conquista; Heliogábalo y Severo Alejandro buscaron un fundamento ideológico diverso, respectivamente el dios solar de la ciudad siriana de Émesa y la ideologia senatorial; Severo Alejandro intentó también en vano restablecer la disciplina militar. Pero el derrumbamiento no se verificó de repente: entre la muerte natural de Septimio Severo (211 d. de C.) y la cruenta de Severo Alejandro (235) pasaron nada menos que 24 años.

Evidentemente la construcción de Severo era sólida y se necesitó un cuarto de siglo de desgaste para abatirla definitivamente.

Como hemos ya dicho, la noche entre el 31 de diciembre del 192 y el dia de año nuevo del 193 , Cómodo fue asesinado por la iniciativa del prefecto del pretorio Quinto Emilio Leto, de Marcia, concubina del emperador, y de Eclecto, su camarero personal (cubicularius), y fue aclamado nuevo emperador a Quinto Helvio Pértinax, prefecto de la ciudad, uno entre los últimos amigos de Marco Aurelio sovrevivientes a la represión feroz practicada por Cómodo.

Según las fuentes, la de Pértinax fue una elección improvisada, como improvisada habria sido también la conjuración ${ }^{36}$. En realidad, esta fue desde luego cuidadosamente preparada, y el mismo Pértinax estaba informado de ella; según la Historia Augusta él conocia lo que se preparaba, pero calló ${ }^{37}$, y un siglo y medio después el emperador Juliano el apóstata lo acusará explícitamente de complicidad ${ }^{38}$.

Según Alfred von Domaszewski la conjuración habria sido preparada para nombrar a Septimio Severo, y la elección de Pértinax habria sido un expediente impensado, impuesto por las circunstancias: cuando los conjurados descubrieron que Cómodo se disponia a matarlos juntos a los nuevos cónsules ordinarios del $193^{39}$, fueron obligados a adelantar su muerte, sin esperar el regreso de Severo, que se encontraba en la provincia de Panonia Superior en funciones de gobernador. Pero esto no es creible: si esperaba su propia aclamación, Severo habría ciertamente considerado la cosa una traición y habria reaccionado con sus legiones, y los conjurados no podian ignorar esto.

Richard Birley derriba la visión de Domaszewski: la conjuración tenia la intención de nombrar al propio Pértinax, y la elección de Septimio Severo después de sólo tres meses fue el verdadero expediente impuesto por las circunstancias, improvisado después de la inesperada y precoz salida de escena de Pértinax. En efecto, como hemos dicho, Pértinax estaba informado de la conspiración desde hace tiempo: según la Historia Augusta ya desde cuando era cónsul ordinario por segunda vez, es decir desde enero del 192 . No hubo alguna anticipación imprevista: la hostilidad del cónsul ordinario del 193 Quinto Sosio Falcón hacia Pértinax 40 indica que el proyecto de matar a los cónsules atribuido a Cómodo era una invención propagandistica difundida por los conjurados para justificarse y no fue la causa imprevista y repentina de la muerte del emperador. La preparación fue ciertamente larga y cuidadosa e implicó la colocación de hombres de confianza en los puestos más importantes: por eso los magistrados del 193, nombrados bajo Cómodo, no fueron reemplazados después de su muerte ${ }^{41}$, evidentemente porque tenian la confianza de los conjurados, que habian dirigido sus elecciones. En efecto, sabemos que Septimio Severo había sido elegido gobernador de Panonia Superior precisamente por el prefecto del pretorio Emilio Leto ${ }^{42}$.

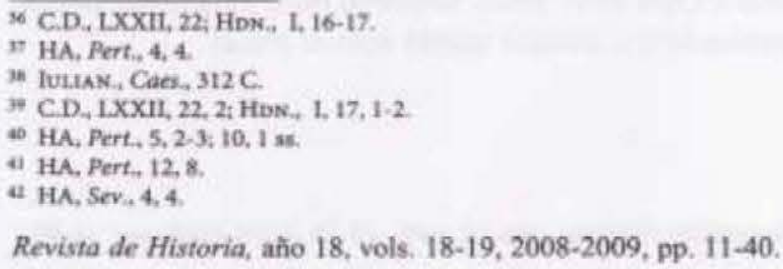


Hasta aquí la tesis de Birley es sin falta aceptable y demuestra la debilidad de la tesis de Domaszewski. Pero no es convincente la idea de que la conspiración fuese organizada por una especie de "partido de los africanos". Según Birley en los puestos más importantes habrian sido colocados sobre todo africanos conectados con Pértinax, que habia sido procónsul de África en el 188-189 d.C.:

1) Quinto Emilio Leto, prefecto del pretorio, era oriundo de Thaenae, ciudad de África proconsular ${ }^{43}$;

2-3) Lucio Septimio Severo, gobernador (legado) de la provincia imperial de Panonia Superior, y su hermano Lucio Septimio Geta, gobernador de Mesia Inferior, eran oriundos de Lepcis o Leptis Magna, ciudad de África proconsular en la Libia actual, y el primero había sido comandante de legión en Siria cuando Pértinax era gobernador de la provincia;

4) Cayo Fulvio Plauciano, quizás entonces prefecto de los vehículos (praefectus vehiculorum), es decir responsable de la red postal del estado, y por eso en condición de controlar la difusión de las noticias, era también oriundo de Leptis Magna y pariente de Septimio Severo y Geta;

5) Décimo Clodio Albino, gobernador de Bretaña, según la Historia Augusta era oriundo de la ciudad africana de Hadrumetum ${ }^{44}$;

6) Tito Aurelio Polo Terenciano, quizás gobernador de Dacia, era tal vez africano y podria haberse encontrado en Bretaña bajo el gobernador Pértinax;

7) Lucio Mantenio Sabino, prefecto de Egipto, era quizás pariente de Pértinax;

8) Aselio Emiliano, procónsul de Asia, era pariente de Clodio Albino ${ }^{45}$.

Este análisis de Birley suscita muchas dudas. Plauciano estaba indudablemente conectado con Septimio Severo, pero desde luego no con Pértinax, por el cual probablemente habia sido condenado en juicio cuando él cubria el cargo de prefecto de África ${ }^{46}$.

El origen africano de Clodio Albino, transmitido por una "Nebenvita", podria ser una invención de la Historia Augusta; lo que es cierto es sólo que uno de los sostenedores de Albino, que se llamaba Clodio Celsino, era oriundo de Hadrumetum ${ }^{47}$. Esta noticia, transmitida por una "Hauptvifa" y por lo tanto muy probablemente auténtica, le sugirió al autor dos noticias muy sospechas: que también Clodio Albino era oriundo de Hadrumetum ${ }^{48}$, y que era nada menos que un hermano de Celsino 49 .

Además, el origen africano de otros personajes, como Tito Aurelio Polo Terenciano y Lucio Mantenio Sabino, es muy hipotético. Pero, sobre todo, no es claro por qué un grupo o "partido" de africanos habria debido sostener a Pértinax, que no era africano y que en su borrascoso proconsulado de África tuvo que sofocar graves sediciones, ni por qué después de la muerte de Pértinax dos probables africanos, como Aselio Emiliano, procónsul de Asia, y Mantenio Sabino, prefecto de Egipto, no apoyaron al africano Septimio Severo. sino más bien al itálico Pescenio Nigro.

La verdad es que había africanos en todas las facciones, es decir entre los sostenedores de todos los pretendientes de 193 (Pértinax, Didio Juliano, Septimio Severo, Pescenio Nigro y Clodio Albino), en consecuencia del ascenso económico y social de las provincias africanas, empezado desde algunos decenios; pero no habia ningún "partido" de africanos, aún porque el mismo concepto de "africano" es una abstracción moderna, que reune de manera arbitraria realidades étnicas muy diferentes, que no eran unidas por ninguna solidaridad patriótica.

La elección de Septimio Severo, Pescenio Nigro y Clodio Albino como gobernadores de las provincias que tenian las guarniciones más numerosas (tres legiones cada una), no fue una consecuencia de su afiliación al pretendido "partido de los africanos", sino más bien del deseo de los conspiradores de evitar el peligro de pronunciamientos militares en las provincias después de la eliminación de Cómodo.

\footnotetext{
4s Cfr. Année epignaphique 1949, 38 .

4t $\mathrm{HA}, A \mathrm{lb}, 1,3 ; 12,8$.

is CD, 1XXIV, 6, 2

4 C.D. IXXIII, 15, 4

6) HA, Sev, 11, 3,

HA, Alb, 1, 3 .

* HA, Alb., 1,3.
} 
Según una intuición de Barnes, el jefe de los conspiradores, el prefecto del pretorio Emilio Leto, se ilusionaba haber elegido a tres personas de escaso valor, hombres sin experiencia militar, sin prestigio ni carisma hacia los soldados, y por lo tanto incapaces de iniciativas arriesgadas. Eso es atestiguado explícitamente con respecto a Pescenio Nigro por Casio Dión, aunque él atribuya este cálculo a Cómodo ${ }^{50}$, $y$ de manera indirecta con referencia a Clodio Albino por Herodiano ${ }^{51}$, que afirma que Albino se distinguia sólo por su nobleza, su cultura y su lujo.

El mismo cálculo tenemos que suponer con respecto a Severo, como indicará el análisis de su carrera: después de un recorrido mediocre y casi totalmente desprovisto de experiencias militares, de repente Severo recibió, en el 192 d. de C., la Panonia Superior, una de las provincias más importantes y delícadas.

Así pues, examinaremos el origen familiar y la carrera politica de Septimio Severo hasta el viraje decisivo del $193 \mathrm{~d}$. de C.

\section{LA CARRERA DE SEPTIMIO SEVERO HASTA EL 193 D. DE C.}

Septimio Severo nació en Lepcis (o Leptis Magna), ciudad de la Tripolitania (actual Libia) en la provincia senatorial de África el 11 de abril del $145 \mathrm{~d}$. de C. Esta fecha, transmitida por Casio Dión ${ }^{52}$, es preferible a la que indica la Historia Augusta, 8 de abril del $146^{53}$. El dia es confirmado por el Feriale Duranum, un papiro hallado en Dura Europos, cerca de la frontera del río Éufrate, con una lista de fiestas públicas celebradas por el ejército en la época de Severo Alejandro. El año parece confirmado por los datos del horóscopo del emperador ${ }^{54}$,

Severo pertenecia a una familia de notables lepcitanos, quizás púnicos romanizados o bien descendientes de mercaderes itálicos, de condición ecuestre; pero ya en la generación de su padre dos parientes, probablemente primos de su padre, ingresaron en el senado y se volvieron cónsules ${ }^{55}$; Públio Septimio Severo fue cónsul sufecto en el $153 \mathrm{~d}$. de C., Cayo Septimio Severo en el 160.

Después del vigintivirado (el primer grado de la carrera senatorial), Severo pudo omitir el tribunado militar ${ }^{56}$ y desempeñar directamente la cuestura: podemos suponer que la desempeñase a la edad minima de 25 años, y por eso en el $170 \mathrm{~d}$. de C., o más exactamente desde el 5 de diciembre del 169 hasta el 4 de diciembre del 170.

Según la Historia Augusta ${ }^{57}$, después de ser cuestor en Roma, Severo fue cuestor por segunda vez y fue destinado a la provincia senatorial de Bética (la actual Andalucia, en la España meridional); pero una invasión de Mauros causó una emergencia militar en esta provincia, que por eso se volvió temporáneamente provincia imperial y fue anexada a Hispania Tarraconense bajo el legado Cayo Aufidio Victorino. En cambio, la provincia imperial de Cerdeña, normalmente gobernada por un simple procurador de rango ecuestre, se volvió temporáneamente provincia senatorial y Severo fue enviado a Cerdefia antes que a Bética, desde el verano del 171 hasta el verano del 172.

Es claro que Severo, desprovisto de experiencia militar, fue considerado inadecuado para la dificil situación de Bética, donde necesitaban hombres militarmente capacitados: gracias al canje entre Bética y Cerdeña, el procurador ecuestre de Cerdeña, que sin duda habia ya desempeñado las tres milicias, es decir los tres comandos militares prescritos para todos los caballeros, fue enviado a Bética, y Severo a Cerdeña, con una sustancial degradación.

Algunos autores no creen a esta doble cuestura de Severo, pero tenemos que pensar que en estos años habia falta de hombres como consecuencia de la peste, y una reiteración de este tipo es muy verosimil.

\footnotetext{
St C.D. LXXV, 6, 1 .

51 How. III, 5,2 y 7,1 .

s2 C.D., LXXVI, 17, 4: LXXVIII, 11, 6

5) $\mathrm{HA}_{4}, \mathrm{SeV}_{4}, \mathrm{I}, 3$.

4 HA, Sex, 2,8 .

55 HA, Sex, 1. 2

36 HA, SeK, 2,3 .

5? HA, SeN, $2,3$.

Revista de Historia, año 18, vols. 18-19, 2008-2009, pp. 11-40.
} 
Luego, Severo fue asesor (legatus) del procónsul de África ${ }^{58}$, en el 173-174 d. de C. La inscripción de un arco erigido en Lepcis (o Leptis Magna) ${ }^{59}$ nos informa que entonces el procónsul era su pariente y casi homónimo Cayo Septimio Severo (primo de su padre, como hemos dicho).

Después de su regreso a Italia, desde el 10 de diciembre del 174 hasta al 9 de diciembre del 175, fue tribuno de la plebe, designado por el mismo emperador Marco Aurelio (es decir fue tribumus plebis candidatus, como atestigua la Historia Augusta ${ }^{60}$ ). Esta designación, signo de un grande favor de parte del emperador, probablemente fue el último fruto de la protección de su pariente más famoso, del cual se pierden las huellas después del 177.

A este periodo se remonta su primer matrimonio ${ }^{61}$, con una mujer de Lepcis que se llamaba Paccia Marciana, como confirman dos inscripciones honorarias de Lepcis y de Cirta.

En el 177, a la edad de 32 años, Severo desempeñó el cargo de pretor, pero esta vez sin la recomendación del emperador ${ }^{62}$. Antes del plazo de su pretura, fue enviado a España Tarraconense como iuridicus, es decir ayudante del gobernador de aquella provincia imperial en la administración de la justicia. Por eso los espectáculos (ludi) que aprestó en Roma en su calidad de pretor se desarrollaron en su ausencia 63 .

Esta superposición de cargos indica de manera muy clara la falta de hombres ocasionada por las exigencias de la guerra contra los Cuados y los Marcómanos; pero nos impresiona el hecho de que él no fue utilizado en el frente danubiano, sino más bien en una provineia pacificada, evidentemente para destinar en la zona de operación a hombres con una mejor capacidad militar.

Sólo después, Severo recibió su primer comando militar, como legatus (comandante) de la cuarta legión escitica (Scythica) ${ }^{64}$, que tenía su base en Palestina, entonces incluida en la provincia imperial de Siria. La fecha más probable son los años 180-182 d. de C., cuando el gobernador (legatus Augusit pro praetore) de aquella importante provincia imperial era Pértinax.

La Historia Augusta ${ }^{65}$ afirma que después del comando en Siria, Severo transcurrió un periodo en Atenas para completar sus estudios y por motivos religiosos y "turisticos" (studionum sacronamque causa et operum et vetustatum). Detrás de esta explicación se esconde probablemente un período de desgracia política por toda la duración de la prefectura del pretorio de Tigidio Perenne; en efecto, la carrera política de Severo quedó "congelada" desde el 182 hasta cerca del 185 , exactamente como aquella de Pértinax 66 .

Después de la caida de Perenne, Severo fue escogido gobernador (legatus Augusti pro praetore) de la provincia imperial de Galia Lugdunense, y desde allá, por el trámite de algunos amigos, pidió la mano de Julia Domna, de la dinastia real đe Ėmesa (actual Homs), una ciudad árabe de Siria 67 . La mujer lo alcanzó en Lyon y fueron celebradas las bodas. Según la Historia Augusta la primera mujer de Severo, Paccia Marciana, habia fallecido.

Desde luego nació el primer hijo, Septimio Bassiano, el venidero Caracalla, que según Casio Dión nació el 4 de abril del $188 \mathrm{~d}$. de C. 68 . Por consiguiente, podemos suponer que Julia Domna hubiera llegado a Lyon en el 187 y que la legación de Severo hubiese empezado en el verano del 186 y hubiese durado almenos hasta el verano del 188.

\footnotetext{
is H, Ser, $2,5$.

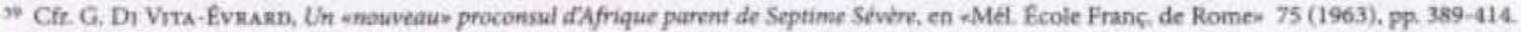

(t) HA, Sev. 3, 1

61. HA, Sev, 3, 2

62 HA, Sev, 3,3

6) $\mathrm{HA}$, Ser, 3, 4-5.

64 HA, Sev, 3,6.

6) HA, Sev, 3, 7 .

at HA, Pert., 2, 11 y 3,3

67 HA, Sev, 3, 8-9

6t C.D. LXXVIII, 6,5
} 
Según lo que afirma la Historia Augusta en la vida de Pescenio Nigro ${ }^{69}$ y en la de Clodio Albino 70 , cuando Septimio Severo era gobernador de Galia Lugdunense, ambos sus venideros rivales Nigro y Albino habían cooperado con él en operaciones militares en territorio gálico en el curso de la denominada guerra de los desertores (bellum desertorum), ocasionada por la rebelión de un militar nombrado Materno. Pero es claro que esta noticia, ausente de la vida del mismo Severo y presente sólo en dos "Nebenviten", es una tipica invención del autor de la Historia Augusta, y no puede de ninguna manera atestiguar alguna actividad militar de parte de Septimio Severo antes de su aclamación imperial.

Después de su regreso en Roma e inmediatamente antes de su envio como procónsul de la provincia senatorial de Sicilia, nació su hijo secundogénito $\mathrm{Geta}^{71}$; la fecha exacta del nacimiento es transmitida por la Pasión de las mártires africanas Felicidad y Perpetua: el 7 de marzo del 189. Por lo tanto el proconsulado de Sicilia, un cargo de duración anual, duró desde el verano del 189 hasta el verano đel 190.

Según la Historia Augusta ${ }^{72}$, durante su proconsulado de Sicilia, Severo fue procesado con la acusación que habia consultado a adivinos o astrólogos acerca de la posibilidad de su ascenso al imperio, pero fue absolvido por el prefecto del pretorio. Esto justifica la sospecha de que haya nacido en esta ocasión su vinculo con el prefecto Emilio Leto, el jefe de la conspiración contra Cómodo, de que hemos ya hablado.

Cierto es que en el 190, evidentemente en la segunda mitad del año, es decir después de su regreso de Sicilia, Septimio Severo cubrió el cargo de cónsul sufecto ${ }^{73}$; el 190 fue el año en que hubo nada menos que 25 cónsules.

Acerca del último grado de su carrera política antes de su ascenso al imperio, la Historia Augusta equivoca hablando de un comando en Germania, después de casi un año de pausa ${ }^{74}$. En realidad, Severo fue escogido gobernador (legatus Augusti pro praetore) de la provincia imperial de Panonia Superior, como afirman más correctamente Casio Dión ${ }^{75}$ y Herodiano ${ }^{76}$ y como confirma la misma Historia Augusta cuando atestigua que Severo fue aclamado emperador por sus tropas en Carnuntum (actual Petronel, no lejano de Viena), que era precisamente la capital de Panonia Superior 77 .

En consideración de que Severo fue cónsul sufecto en la segunda mitad del 190 y que después se mantuvo sin cargos por casi un año, podemos suponer que hubiera tomado posesión de la legación de Panonia en el verano del 192, sólo ocho meses antes del dia en que fue aclamado emperador, el 9 de abril del 193.

Como hemos ya dicho hablando del pronunciamiento que ocasionó la muerte de Cómodo, es muy probable que la nominación de Severo en una provincia estratégica como la Panonia Superior, guarnecida por tres legiones, fuera decidida por los conjurados en el ámbito de una cuidadosa preparación del golpe de estado. EI hecho de que ellos escogeron a un hombre sin experiencia militar como Septimio Severo demuestra que él fue escogido exactamente por su inexperiencia, es decir porque fue considerado absolutamente incapaz de intentar la escalada al poder. Es inútil decir que este cálculo era tremendamente equivocado.

\section{LA CARRERA DE PUBLIO HELVIO PÉRTINAX ANTES DE SU ACLAMACIÓN IMPERIAL}

Por lo tanto, es muy interesante una comparación entre la carrera de Severo y la de otro protagonista de los trágicos acontecimientos del 193, Publio Helvio Pértinax, que fue aclamado emperador inmediatamente después de la muerte de Cómodo.

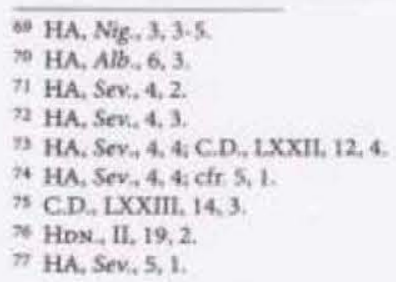

Revista de Historia, año 18, vols. 18-19, 2008-2009, pp. 11-40. 
Conocemos su carrera gracias a una inscripeión hallada en Brühl, cerca de Colonia, en la provincia de Germania Superior, ahora conservada en el Museo de Bonn ${ }^{78}$. Como en muchos otros casos, la documentación epigráfica completa y precisa lo que afirman las fuentes literarias, en este caso sobre todo la Historia Augusta.

Según la práctica normal de las inscripciones romanas grabadas sobre las bases de estatuas honorarias, son mencionados todos los cargos y comandos del personaje honrado, en el preciso orden de sucesión cronológica, desde el menos importante al más importante, o también viceversa.

El texto de Brühl, lleno de lagunas, se puede reconstruir de esta manera: "A Publio Helvio Pértinax, caballero con caballo público, prefecto de la séptima cohorte de Galos provista de caballería, tribuno de la sexta legión Victoriosa, prefecto de la primera cohorte de Tungros, prefecto del escuadrón de caballeria... [aquí falta el nombre del escuadrón], procurador encargado de la organización de las alimentaciones (alimenta), prefecto de la flota de Germania, procurador del emperador enviado a Dacia con un salario de 200.000 sestercios anuales, los ciudadanos de Colonia han erigido esta estatua con dinero público fo bien, a él como patrono]".

En esta inscripción, que se remonta probablemente al $169 \mathrm{~d}$. de C., Pértinax es todavia un caballero sin ser aún un senador. Ésta ha sido colocada por los ciudadanos de Colonia cuando Pértinax se encontraba todavia alli como almirante de la flota fluvial del Rin, pero a punto de trasladarse a Dacia para desempeñar el cargo sucesivo de procurador imperial.

La primera cosa que nos impresiona es la falta de la filiación entre el nombre de familia Helvio y el cognomen Pértinax, quizás una confirmación del hecho de que él era de origen humilde, como afirma Casio Dión ${ }^{79}$; es más, según la Historia Augusta ${ }^{80}$, Pértinax era hijo de un liberto.

Su condición ecuestre es señalada por la fórmula "caballero con caballo público", que deriva del uso militar de la época republicana, cuando los ciudadanos acomodados inscritos en las 18 centurias de caballeros combatian en la caballeria y el caballo era provisto y mantenido por el estado, gracias a un impuesto pagado por las viudas.

En esta época, la pertenencia al orden ecuestre necesitaba un rédito de almenos 400.000 sestercios anuales, que en el caso de Pértinax era probablemente producido por la actividad comercial de su padre, que en Liguria vendia y quizás también producia prendas pesadas de fieltro. Pero Pértinax fue el primer caballero de su familia, porque su padre, como liberto, no podia. Tenemos que suponer que él fue admitido en el orden ecuestre por concesión del emperador, al cual, desde la abolición de los censores, pertenecía la tarea de compilar las listas de los caballeros y senadores.

Desde el tiempo del emperador Claudio, la carrera de un caballero empezaba obligatoriamente con tres comandos militares o milicias (tres militiae). El primer comando (militia prima) era el de un contingente de tropas auxiliares de infantería de unos quinientos provinciales desprovistos de la ciudadanía romana (cohors quingenaria); el título del comandante era prefecto de cohorte.

El segundo comando (militia secunda) era el grado de tribuno militar en una legión de ciudadanos romanos, o bien el comando de una cohorte auxiliar de infanteria con efectivos dobles, unos mil provinciales (cohors milliaria); el título era tribuno de cohorte miliaria. En cada legión habia seis tribunos militares: cinco de condición ecuestre y uno sólo destinado a la carrera senatorial. El signo exterior de esta diferencia era la laticlavia, es decir la faja de púrpura que adornaba el traje civil de estos oficiales, la toga: la del futuro senador era ancha (latus clavus), la del simple caballero estrecha (angustus clavis).

El tercer comando (militia tertia) era el comando de un escuadrón auxiliar de caballeria de unos quinientos provinciales (ala), con el titulo de prefecto de ala.

Habia también la posibilidad, pero no la obligación, de un cuarto comando (militia quarta), el de un ala milliaria, es decir de un escuadrón de caballeria auxiliar con efectivos dobles.

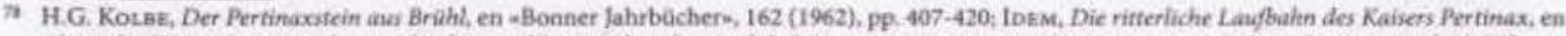
Akten des IV. Int, Kangrear für griechischen und lateinischen Epigrapìik, Wien 1964, pp. 185-191; G. At.rötox, P. Heivitus Pertinax und M. Valerias

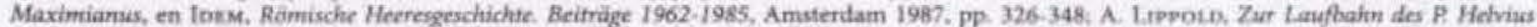
Pertinax, en Bonser Historia-Augusta Collogutum 1979. 1981. Bonn 1983, pp. 173-191.

No C.D, LXXI, 22, 1; LXXII, 3, 1.

to HA, Pert. 1, 1.
} 
Después de estos comandos, el caballero podia acercarse a los cargos civiles, como procurador en la administración imperial, y a las prefecturas superiores, que podian culminar con la prefectura de Egipto y la prefectura del pretorio. Los cargos de procurador, como las prefecturas superiores, eran clasificados jerárquicamente segùn el salario cobrado, que podia ser de $60.000,100.000,200.000$ o 300.000 sestercios anuales.

En el caso de Pértinax la militia prima fue la prefectura de la sexta cohorte de Galos, estacionada en Siria; la Historia Augusta ${ }^{81}$ confirma que èl comandó una cohorte en Siria.

Cada cohorte era señalada por un número y por la indicación del pueblo de su reclutamiento inicial, por ejemplo los Galos, aunque después ésta fuese reclutada también en otras regiones del imperio. El número de la cohorte que comandó Pértinax indica que había por lo menos siete cohortes col mismo nombre; por otra parte, la especificación "de Galos" no implica que al tiempo de Pértinax la cohorte fuese reclutada todavía sólo en Galia.

En algunos casos se añadia una indicación sobre el tipo de armamento (por ejemplo sagittariorum, es decir "de arqueros") o la presencia de un pequeño contingente de caballeros, como vemos precisamente en esta cohorte de Pértinax, "provista de caballeria" (equitata).

La Historia Augusta 82 afirma que Pértinax empezó este primer comando bajo Antonino Pio (por lo tanto antes de $161 \mathrm{~d}$. de C.), pero añade que él combatió valiosamente en la guerra pártica de Lucio Vero $\left(162-166 \mathrm{~d}\right.$. de C.) y por eso fue ascendido a un comando en Bretaña ${ }^{83}$. La inscripción de Brühl-Colonia nos permite precisar que este segundo comando (militia secunda) fue el de tribuno militar de rango ecuestre (angusticlavius) en la sexta legión Victoriosa, estacionada en Eburacum, hoy día York.

También las legiones eran señaladas por un número, pero a ello se añadía un epiteto que subrayaba su valor (come nuestro "Victoriosa") o su particular vinculo de fidelidad con el emperador (por ejemplo "Devota y Fiel", en latino Pia Fidelis).

Antes de pasar a la militia tertia, Pértinax reiteró la militia secunda y fue prefecto de una cohorte milliaria de infanteria; según la Historia Augusta ${ }^{84}$, también este comando estaba en Bretaña, y por eso podemos reconstruir el nombre de esta cohorte, casi ciertamente la cohorte primera de Tungros, que estaba estacionada en Bretaña y cuyo comandante se llamaba prefecto antes que tribuno, como los de las otras cohortes de mil hombres. Los Tungros eran un pueblo de la provincia de Germania Inferior, cerea de la pequeña ciudad actual de Tongres / Tongern, en la Bélgica. Pero al tiempo de Pértinax estas cohortes no se reclutaban ya sólo entre los Tungros.

El traslado de Pértinax de Siria a Bretaña probablemente pasó antes del término de la guerra pártica, y él quedó en la isla desde el 164 hasta el 166, los años de la reocupación de la línea fortificada de Adriano (vallum Hadriani): y precisamente alli estaba estacionada la primera cohorte de Tungros.

El tercer comando (militia tertia) de Pértinax fue la prefectura de un escuadrón de caballeria, cuyo nombre no es conservado. Pero la Historia Augusta 85 afirma que esta ala era en Mesia, probablemente Mesia Superior, Serbia de hoy. Un indicio de su viaje de llegada o de vuelta podria ser una inscripción que fue dedicada por él, con el título genérico de prefecto no mejor determinado, en un santuario de Sirmium (acerca de la actual Sremska Mitroviça en Vojvodina, al Oeste de Belgrado), en la provincia cercana de Panonia Inferior ${ }^{86}$, donde se encontraba como gobernador su protector Tiberio Claudio Pompeyano. En efecto, Casio Dión nos informa que Pértinax recibió las milicias ecuestres gracias a la protección de Pompeyano ${ }^{87}$. Pues es natural de suponer que Pértinax haya parado en Sirmium para hacerle homenaje y agradecerlo de su propio nombramiento. La fecha de esta permanencia en Mesia Superior es probablemente el 166-167 d. de C.

Luego la inscripción de Brühl-Colonia menciona el primer cargo procuratorio de Pértinax, el de procurador para los alimenta, el complejo sistema de préstamo agrario facilitado creado por Nerva y Trajano para favorecer el desarrollo de la producción agricola y el incremento demográfico de Italia, y asi contrastar su inexorable decadencia económica y su despoblamiento. El emperador otorgaba un préstamo a los

\footnotetext{
4) HA, Pert, 1. 6.

62. HA, Pert., 1.6 .

6s HA, Pert, 2, 1 .

4 HA. Pert, 2, 1 .

* HA, Pert., 2, 2

(s) CII, III, 3232(=II, , 407).

a) CD. LXXII, 3,1 .
} 
hacendados para sanear o irrigar sus tierras y recuperar las baldias; el interés de cinco por ciento anual (un interés particularmente bajo en el mundo antiguo) era depositado en una caja especial destinada a suvencionar el sustento (alimenta o alimentationes) y la educación de jóvenes. La organización general de los alimenta era confiada a un experto senador que hubiera ya sido cónsul, con el título de prefecto de los alimentos (praefectus alimentorum); de él dependian algunos procuradores ecuestres (procuratores ad alimenta), cada uno con competencia en un preciso ámbito territorial.

La Historia Augusta ${ }^{88}$ nos permite afirmar que Pértinax fue encargado de supervisar los alimentos en los territorios a lo largo de la via Aemilia, el camino desde Ariminum / Rimini, sobre la costa del mar Adriático, hasta Placentia / Piacenza, a través de Bononía / Bologna, Mutina / Modena y Parma / Parma: prácticamente, el territorio de la actual región italiana que se llama Emilia como el camino antiguo. La fecha de este cargo de Pértinax es probablemente el 167-168 d. de C., cuando Marco Aurelio establecía su cuartel general en Aquileia después de la incursión de Cuados y Marcomanos a Italia.

Inmediatamente después, Pértinax fue escogido para su primer comando superior (con salario de 100.000 sestercios anuales), como prefecto de la flota imperial de Germania, estacionada sul rio Rin en Altenburg, acerca de Colonia, capital de Germania Inferior. La inscripción hallada acerca de Colonia confirma asi la noticia de la Historia Augusta 89 .

Como hemos ya dicho, cuando la inscripción fue grabada (169 d. de C.?) Pértinax estaba todavia en Colonia en funciones de almirante de la flota fluvial, pero acababa de ser ascendido al cargo de procurador provincial de Dacia, es decir responsable de la gestión financiera en aquella provincia imperial. Esta parte de la inscripción es muy lagunosa, pero la confrontación con lo que afirma la Historia Augusta 90 nos permite reconstruir el texto: mientras normalmente el procurador de Dacia cobraba un salario de 100,000 sestercios anuales, Pértinax recibió el privilegio excepcional de un salario doble, de 200.000 sestercios anuales.

Quizás en estos años la provincia de Dacia constituía la zona de retaguardia para los ejércitos en guerra, y el papel del procurador tenia una grande importancia para los abastecimientos. La fecha más probable es el 169-170 d. de C., y de todos modos después de la muerte de Lucio Vero (enero o febrero del 169), porque el título que leemos en la inscripción de Brühl-Colonia es "procurador del emperador" y no "de los emperadores".

Aquí terminan las informaciones de la inscripción de Brühl. Pero hemos comprobado que las que ella provee confirman sustancialmente las noticias de la Historia Augusta; por lo tanto, se puede considerar fidedigno también lo que esta última fuente afirma acerca de los grados siguientes de la carrera de Pértinax. parcialmente confirmado también por Casio Dión.

Antes de todo, gracias a su protector Claudio Pompeyano, que después de la muerte de Lucio Vero sc trasformó en hierno del emperador Marco Aurelio, casándose con su hija Lucila, la viuda de Lucio Vero, Pértinax fue escogido comandante de un cuerpo de armada formado por destacamentos (vexillationes) de algunas legiones con el titulo de praepositus o dux vexillationum, comandante de destacamentos 91 .

Por su éxito al frente, él fue nombrado senador ${ }^{92}$, probablemente con la admisión (adlectio) en la categoría de los tribunicios, es decir de aquellos que habian ya desempeñado el cargo de tribuno de la plebe. Luego el dichoso éxito de otras operaciones militares le procuró la admisión (adlectio) en la categoria superior de los pretorios, aquellos que habian ya desempeñado el cargo de pretor ${ }^{93}$.

Estas campañas como comandante de vexillationes y estos dos ascensos se remontan probablemente al 170-171 d. de C. Después de convertirse pretorio. Pértinax fue escogido comandante de una legión (legatus legionis), que según la Historia Augusta 94 era una legión primera, y con ella completó la liberación de Raetia y Nórico (actuales Suiza, Bavaria y Austría). Probablemente esta "legión primera" era la "legión primera ayudante" (legio I Adiutrix), estacionada en Panonia Superior en Brigetio, actual Szóny en Hungria, y las operaciones se remontan al 171 o $172 \mathrm{~d}$. de C.

\footnotetext{
" HA, Pert, 2.2.

av HA, Pert, 2, 3.

* HA, Pert., 2, 4

i) HA. Pert, 2, 4

") HA, Port, 2, 5 .

93 HA, Pert. 2, 6 .

4 HA, Pert., 2, 6.
} 
Luego él fue empleado contra los Cuados y los Naristas; según San Jerónimo ${ }^{95}$, en el 172 d.C. Pértinax era el comandante romano en el famoso episodio del milagro de la lluvia, narrado por Casio Dión y la Historia Augusta 96 y otras fuentes ${ }^{97}$ y representado figurativamente en la columna antonina, todavia visible en Roma en la Plaza Colonna. En aquella ocasión el ejéreito romano, rodeado por el enemigo y atormentado por la sed y el calor, estaba a punto de ceder a los bárbaros, pero una lluvia providencial reanimó a los Romanos y trastornó a los bárbaros, que fueron derrotados. Hubo también una polémica entre cristianos y paganos, porque ambos reivindicaban el mérito de haber obtenido con sus plegarias el milagro.

Pértinax siguió combatiendo hasta el $174 \mathrm{~d}$. de C. y en la primera mitad del 175 fue escogido cónsul $^{98}$. En el mismo año acompañó a Marco Aurelio en su expedición en Oriente contra el rebelde Avidio Casio, que fue asesinado por sus mismos soldados antes de la llegada de Marco Aurelio, y luego de Siria regresó al frente "para defender el Danubio": así afirma la Historia Augusta 99 , y tenemos que pensar de nuevo al comando de un cuerpo de armada de vexillationes en Panonia, quizás en el 176-177 d. de C.

Después de este comando, Pértinax fue escogido gobernador (legatus Augusti pro praetore) de Mesia $(177-178 \mathrm{~d}$. de C.?); la Historia Augusta 100 añade que él gobernó simultáneamente ambas provincias imperiales de Mesia: Mesia Superior, que corresponde a Serbia actual, una provincia de rango pretorio con sólo una legión, y Mesia Inferior, actual Bulgaria, una provincia de rango consular, con dos legiones, por un total de tres legiones y muchas unidades de tropas auxiliares. Desde luego esta reunión era una decisión excepcional y temporánea, dependiente de las exigencias de la guerra.

Después de poco, Pértinax pasó a Dacia, actual Romania ${ }^{101}$, otra provincia imperial de rango consular con dos legiones, donde se encontraba todavia en funciones el $1^{\circ}$ de abril del $179 \mathrm{~d}$. de $\mathrm{C}$., como nos atestigua un diploma militar ${ }^{102}$, es decir una certificación de licenciamiento de un soldado auxiliar.

Antes de la muerte de Marco Aurelio (17 de marzo del $180 \mathrm{~d}$. de C.), Pértinax fue escogido gobernador (legatus Augusti pro praetore) de Siria ${ }^{103}$, una provincia muy importante a la frontera con los Partos, guarnecida por tres legiones. Allí quedó también en los primeros anios del reinado de Cómodo, quizás hasta el $182 \mathrm{~d}$. de C., cuando Tigidio Perenne se volvió prefecto del pretorio. Por toda la duración de esta prefectura, Pértinax permaneció sin cargos. Según la Historia Augusta ${ }^{104}$, él fue obligado por el potente prefecto de retirarse en su propiedad paterna en Liguria, donde quedó por tres años, probablemente hasta el $185 \mathrm{~d}$. de C.

Después de la caida de Perenne (185), Pértinax pudo remprender su carrera y alcanzó los grados más prestigiosos. Antes de todo fue escogido gobernador (legatus Augusti pro praetore) de la provincia imperial de Bretaña, otra provincia con tres legiones, donde tenió que afrontar una sedición de los soldados y hasta rehusar su propia aclamación imperial ${ }^{105}$. Por eso él pidió y obtuvo ser exonerado de este cargo ${ }^{106}$, que evidentemente pudo durar poco, quizás sólo un año, el $185-186 \mathrm{~d}$. de C.

La insubordinación de las tropas estacionadas en Bretaña es confirmada también por Casio Dión ${ }^{107}$. Tenemos que subrayar que estas tropas se habian rebelado ya antes de la llegada de Pértinax, en el $182 \mathrm{~d}$. de C., y habian intentado (en balde) aclamar emperador a un comandante (legado) de legión llamado Prisco ${ }^{108}$, que se identifica con Tito Caunio Prisco, premiado por su fidelidad a Cómodo con el consulado en el $187 \mathrm{~d}$. de C. 109

De regreso a Italia, Pértinax fue escogido prefecto para los alimentos (praefectus alimentorum) ${ }^{110}$, es decir por acerca de un año ( $187 \mathrm{~d}$, de C.) asumió la entera responsabilidad de aquella organización al interior de la cual, aún como caballero, habia administrado la región a lo largo de la via Aemilia.

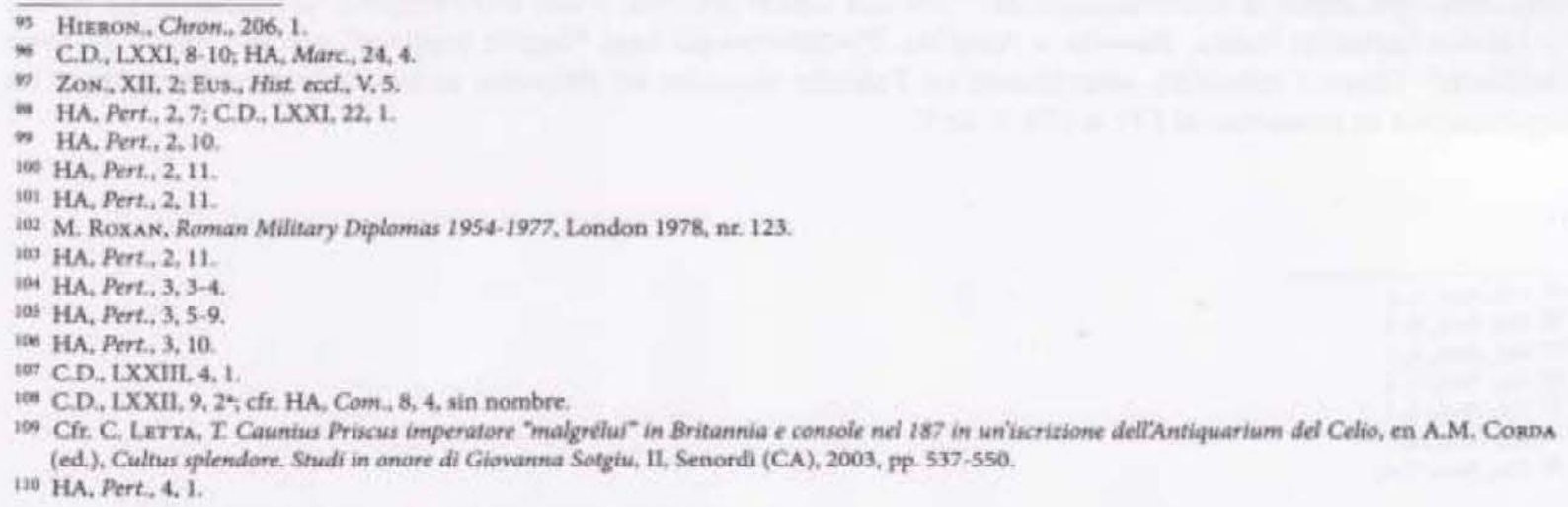

Revista de Historia, año 18, vols. 18-19, 2008-2009, pp. 11-40. 
Luego fue escogido gobernador (procónsul) de la prestigiosa provincia senatorial de África, donde según la Historia Augusta ${ }^{111}$ tenió que reprimir multas rebeliones y según Casio Dión ${ }^{112}$ condenó en juicio a un tipo nombrado Fulvio, quizás Fulvio Plauciano, el pariente y futuro prefecto del pretorio de Septimio Severo. La fecha de este proconsulado se puede establecer en el 188-189 d. de C. gracias a una lista de procónsules de África que nos abastece el escritor cristiano Tertuliano 113 y a una inscripción hallada en la ciudad africana de Thuburbo Maius que nos permite fechar en el 190-191 el proconsulado de Cayo Cingio Severo ${ }^{114}$. Ya que la lista de Tertuliano menciona en sucesión a Pértinax, a Didio Juliano (el sucesor de Pértinax también como emperador) y finalmente a Cingio Severo, podemos afirmar que, si Cingio fue procónsul en el 190-191, ciertamente Didio Juliano estuvo en funciones en el 189-190 y Pértinax en el 188$189 \mathrm{~d}$. de C.

Finalmente Pértinax fue escogido, en el 190 o 191, prefecto de la ciudad de Roma (praefectus $u r b i)^{115}$, el cargo más prestigioso por un senador, que implicaba el comando de las cohortes urbanas (el segundo cuerpo de tropas presente en Roma después de los pretorianos), para asegurar el orden público, e implicaba también la posibilidad de hacer las veces del emperador durante su ausencia de la capital.

Mientras mantenia este cargo, Pértinax fue escogido también cónsul por segunda vez, y precisamente cónsul ordinario como colega del emperador Cómodo, asumiendo el cargo el primer día de enero del $192 \mathrm{~d}$. de C. Esto fue el último ascenso de Pértinax antes de su efimera aclamación imperial, en el curso de la carrera absolutamente extraordinaria de un hombre que en su origen no era ni siquiera un caballero.

Es claro que esta carrera fue fundamentada sólo sobre sus capacidades militares. Casi todos los comandos que él desempeñó eran en zona de operaciones, ya desde las denominadas tres milicias. Él participó en la guerra pártica de Lucio Vero como prefecto de la séptima cohorte de Galos; en la reocupación de la línea fortificada de Adriano en Bretaña como tribuno de la sexta legión Victoriosa y como tribuno de una cohorte miltiaria de Tungros; en todas las fases de las guerras danubianas de Marco Aurelio, primero en zona de retaguardia como prefecto de la flota imperial de Germania, y después al frente, como comandante de destacamentos (vexillationes) y como legado de legión, contra Cuados, Naristas y Sármatas; en la expedición oriental contra el rebelde Avidio Casio; en las últimas fases de las guerras danubianas, de nuevo como comandante de vexillationes y después como gobernador de ambas las provincias de Mesia, con un total de tres legiones.

Precisamente por estas sus capacidades militares fue premiado tanto por Marco Aurelio que por Cómodo, primero con el ingreso en el senado, y después con los cargos senatoriales más importantes y prestigiosos: fue gobernador de las provincias imperiales más importantes militarmente (Mesias, Dacia, Siria, Bretaña) y de la provincia senatorial más prestigiosa (África), cónsul por segunda vez como cónsul ordinario y colega del emperador, y finalmente prefecto de la ciudad de Roma, el ápice de la carrera senatorial.

En total, Pértinax habia tenido el comando de nada menos que doce legiones y tres cuerpos de armada formados por destacamentos legionarios, además de muchísimos cuerpos de tropas auxiliares y de las cohortes urbanas de Roma: en la práctica, él habia comandado y conocía personalmente casi la mitad de todas las fuerzas armadas de Roma.

\section{CONFRONTACIÓN ENTRE PÉRTINAXY SEVERO}

La confrontación entre la carrera de Pértinax y la de Septimio Severo evidencia un contraste enorme. Ambos eran "hombres nuevos" (homines novi), es decir los primeros de su familia que ingresaron en el senado, aunque sólo Severo fuera de condición ecuestre ya desde el nacimiento.

Pero, mientras Pértinax ingresó en el senado exclusivamente por sus capacidades y sus méritos, que indujeron al emperador a ordenar su ascenso (adlectio) cuando era ya un hombre hecho, al contrario Septimio Severo ingresó alli cuando era muy joven y sólo por la recomendación de dos parientes influyentes, que indujeron al emperador a concederle la laticlavia.

De nuevo por recomendación Severo pudo sustraerse al servicio militar como tribuno en una legión, y obtener algunas distinciones formales, como el cargo de legado del procónsul de África, su pariente y casi homónimo Cayo Septimio Severo, y la presentación como candidato del emperador en la elección de tribuno

ii HA, Pert., 4, 1-2.

In C.D. IXXIII, 15, 4 .

13 Tekr., ad Scap., 4, 3 ,

116 Cfr. C. Letra, Il.Afr, 265 e il proconsolato dAfrica di C. Cingje Severo, en - Latomuse 54 (1995), 4, pp. 864-874, particularmente pp. 871 s.

us HA, Pert, 4, 2; cft. How, II, 2, 7; Aun. Vict, Cass, 17, 10, Epit., 18, 4 etc

Revista de Historia, aho 18, vols. 18-19, 2008-2009, pp. 11-40. 
de la plebe, Pero sustancialmente su carrera fue mediocre y totalmente falta de gloria militar.

También Pértinax fue recomendado por protectores potentes, particularmente por Claudio Pompeyano, hierno del emperador Marco Aurelio, pero sólo por su competencia militar y sus merecimientos en el campo, no por un vinculo de parentela.

En el caso de Severo, la omisión del tribunado militar con aparencia aceleró su carrera, porque pudo cubrir directamente la cuestura (probablemente después del vigintivirado, que la Historia Augusta no recuerda), pero ocasionó también una especie de degradación cuando en sustitución de Bética recibió Cerdeña, porque no fue considerado al nivel de la emergencia militar producida por la invasión de los Mauros en Bética.

Lo mismo se puede decir de su envio a Tarraconense antes del término de su pretura: en un momento de grave escasez de hombres, en consecuencia de la peste y de las guerras danubianas, no se recurrió a él para tareas militares, sino sólo para tareas civiles en una provincia tranquila. Probablemente él sustituyó alguien llamado al frente danubiano porque era considerado militarmente más capaz.

En efecto, Severo no fue empleado jamás en guerra. Su primer comando militar, el de legado legionario de rango pretorio, llegó sólo tarde, a los 35 años, y fue desempeñado en tiempo de paz en la provincia de Siria. Después del período de interrupción de su carrera por tres años, él recibió solamente provincias menores: la provincia imperial de Lugdunense (donde, como hemos ya dicho, no participó de alguna manera en operaciones bélicas, a pesar de lo que afirma la Historia Augusta) y la senatorial de Sicilia. Fue cónsul sufecto en el 190, cuando llevaba los 45 años, mientras por los hombres nuevos como él la edad canónica era los 42 años, reducible a 37 o 38 si habian cubierto cargos militares importantes. Evidentemente Severo no pudo recobrar los tres años de la interrupción de carrera sufrida durante la prefectura del pretorio de Tigidio Perenne, ni aprovechar las facilitaciones establecidas por la ley Papia Popea, del tiempo de Augusto, gracias a la cual aquellos que tenian hijos varones vivientes podian cubrir los cargos un poco antes de la edad mínima requerida: eso aunque Severo tuviese ya dos hijos varones, nacidos en el 188 y en el $189 \mathrm{~d}$. de C.

Por eso quedamos muy sorprendidos por el increible salto que le permitió a Septimio Severo, a pesar de su casi total inexperiencia militar, de recibir la provincia de Panonia Superior, una de las más importantes (y más cercana de ltalia), guarnecida por tres legiones y muchas formaciones de tropas auxiliares.

Como hemos ya dicho, Severo tomó posesión de su legación probablemente en julio del 192, y esta fecha explica los motivos verdaderos de su elección: él fue escogido por los conjurados que estaban a punto de matar a Cómodo, como atestigua explícitamente la Historia Augusta, que habla de la recomendación del prefecto del pretorio Emilio Leto ${ }^{116}$. Si consideramos su carrera anterior, es claro que no podemos decir que él fue escogido aunque fuera militarmente inexperto, sino mas bien porque era inexperto, y por lo tanto no era considerado peligroso confiarle el comando de tres legiones y muchos cuerpos de tropas auxiliares en una provincia bastante cercana de Italia.

Por lo tanto, en el 193 d.C., Septimio Severo aparecia absolutamente falto de "chances", es decir de posibilidades en la lucha por la sucesión a Cómodo. Al contrario, todos los antecedentes parecian favorecer a Pértinax como el candidato más fuerte.

En teoria, Pértinax podía contar con el apoyo del ejército, por su prestigio de comandante experto y victorioso y por sus vinculos personales con casi la mitad de los soldados de las fuerzas armadas romanas, mientras Severo parecia destinado a ser rechazado por su falta de capacidad, experiencia y prestigio.

En realidad, muy pronto Pértinax desilusionó a todos, ejército incluido, porque insistió demasiado rigidamente sobre la disciplina militar y decepcionó las expectativas económicas de los soldados, sobre todo de los pretorianos. Por otra parte, ya anteriormente él habia descontentado a los soldados por su disciplina demasiado rigida, como demuestran las sediciones que debió reprimir en Bretaña como legado imperial y en África como procónsul: según la Historia Augusta 117, él pidió ser exonerado del comando de Bretaña "porque las legiones le eran hostiles por su defensa de la disciplina militar".

Septimio Severo, al contrario, supo conquistarse el favor del ejército de una manera duradera y no efimera con una serie de jugadas vencedoras sugeridas por una exacta estima de las fuerzas presentes en el campo.

Plenamente consciente del hecho de que no era un genio en el campo de la guerra y no tenia ni experiencia ni prestigio, él debió su éxito a su profunda intuición política, sea por la capacidad de análisis, sea por las decisiones. Esto nos permite parangonarlo con Augusto, que venció la más terrible guerra civil aunque no tuviera capacidades militares.

\footnotetext{
1\% HA. Sev. 4.4.

is HA, Pert, 3, 10.

Revista de Historia, año 18, vols, 18-19, 2008-2009, pp. 11-40.
} 
Severo comprendió plenamente: 1) el poder creciente del ejército como interlocutor y como protagonista político; 2) su capacidad de presión y condicionamiento, sin comparación con los otros grupos sociales; 3) su importancia creciente por la seguridad del imperio después del trauma de las invasiones barbáricas bajo Marco Aurelio; 4) su potencial económico con referencia a los suministros y como polo de desarrollo y fuerza de trabajo; 5) la preponderancia de las legiones panónicas sobre las otras, que preparaba el ascenso de los emperadores "ilíicos".

Pero al mismo tiempo él supo habilmente "cabalgar el tigre", es decir supo explotar el ejército, sin dejarse revolver $\mathrm{y}$ aplastar: se conformó con gran flexibilidad a sus exigencias, dejándose condicionar por ellas, almenos parcialmente; por eso en muchos episodios de insubordinación o de amotinamiento de sus tropas 118 no reaccionó con el "puño de hierro", sino más bien cedió parcialmente a sus solicitudes y aguardó el restablecimiento del orden antes de que castigase pocos "chivos expiatorios", de modo que no exasperó jamás el descontento de los militares, ni siquiera perdió su respeto ni su estima, y por lo tanto mantuvo siempre el ascendiente y el carisma que tenía hacia ellos.

Por toda la duración de su reinado él actuó sistemáticamente una politica de concesiones a los soldados que le procuraron su gratitud y una inmensa popularidad. Antes de todo él otorgó donativos frecuentes y ricos ${ }^{119}$ y aumentó el salario ${ }^{120}$, bloqueado desde el tiempo del emperador Domiciano (81-96 d.C.), elevándolo de 300 hasta 400 o 450 denarios anuales (es decir de 1200 hasta 1600 o 1800 sestercios).

Además, Severo les aseguró una mejora del sustento, gracias a la reorganización de los abastecimientos de vituallas (annona militaris) y a la asignación de tierras que podian ser cultivadas por los soldados en servicio.

A los militares fue concedido el derecho de contraer matrimonios legitimos durante el servicio ${ }^{121}$; hasta entonces estaba en vigor la prohibición establecida por Augusto ${ }^{122}$ para impedir el aburguesamiento del ejército, y por consiguiente en los pueblos acerca de las bases legionarias (canabae) habia mujeres e hijos no reconocidos por la ley, que no podian heredar legítimamente del soldado caido. Por lo tanto, la innovación introducida por Severo fue ciertamente muy apreciada.

Él abrió perspectivas nuevas de adelantamiento por los militares de tropa a través de la valorización de los graduados (principales) con encargos especiales, salarios más altos y exenciones de las "corvées" y del servicio ordinario. A estos graduados fue concedido el derecho de agregarse en asociaciones o club (en latino collegia), que tenian su caja con función de banca; muchas inscripciones atestiguan el nacimiento bajo Septimio Severo de asociaciones de este tipo, antes prohibidas.

La dignidad de los principales, de los centuriones y de los primipili (el primus pilus era el centurión de grado más alto de cada legión) fue elevada con signos exteriores y otras formas de distinción pública: todos los centuriones pudieron participar en las paradas militares ecuestres (decursiones) poniéndose vestidos blancos (albata decursio), hasta entonces reservados a los oficiales ecuestres y a los primi pili ${ }^{123}$; los centuriones y los principales pudieron exhibir un anillo de oro (anulus aureus), hasta entonces signo distintivo de los caballeros: prácticamente, de esta manera ellos fueron introducidos en el orden ecuestre. al emperador.

Además, Severo acuñó algunas monedas que celebraban particulares legiones, su valor $\mathrm{y}$ su fidelidad

Finalmente, él concedió a los veteranos la inmunidad, es decir la exención de las obligaciones fiscales y de servicios hacia su propia ciudad. A consecuencia de eso, muchos hombres eran atraidos por el reclutamiento en el ejército, donde cada uno podía elevarse en grado, realizar ahorros conspicuos y recibir al momento de su licenciamiento un sustancioso premio de despedida, que le permitia transformarse en acomodado y respetado ciudadano de su propia ciudad de origen o de otra donde podia establecerse.

De esta manera Septimio Severo satisfacia las exigencias del estado, preocupado de sobrepasar las graves dificultades de reclutamiento que sufría del tiempo de Marco Aurelio; pero al mismo tiempo buscaba también el consenso del ejéreito para sí mismo y su dinastia, un consenso indispensable para que su poder se volviese estable y su dinastia arraigase de manera definitiva.

Además, él supo explotar la rivalidad entre los pretorianos y los legionarios. Hasta su reinado, los

\footnotetext{
II" HA, Sev, 8, 9: CD, LXXXV, 10, 2-3;11-13.

119 C.D, XIVI, 6-7; LXXIV, 2, 3; LXXVI, 1, 1; LXXVIII, 36, 2; HA, Sev, 7, 6-7; 16, 5 .

i20 CD, 1XXVIII, 12, 7; 28, 3; 36, 2-3; HoN, III, 9, 5; HA, Sev, 12,$2 ; 17,1$.

12i. HDN, III, 8, 5.

12 C.D., LX, 24,3

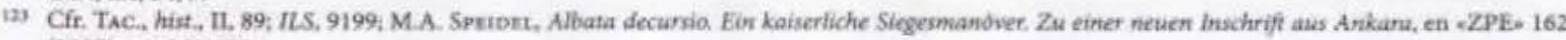
(2007). pp. 263-270.
} 
pretorianos eran reclutados todavia casi sólo en Italia y tenian una posición absolutamente privilegiada respecto a los legionarios estacionados a lo largo de los confines, expuestos a un clima generalmente más riguroso y continuamente en contacto con bárbaros hostiles. Por eso entre los legionarios habia envidia y rencor hacia los pretorianos.

Cuando acababa de ingresar en Roma, Septimio Severo despedió a todos los pretorianos itálicos y formó cohortes pretorias nuevas con los soldados mejores y más fieles de sus legiones ${ }^{124}$, sobre todo panónicas, y desde entonces el ascenso de una legión a una cohorte pretoria se volvió una perspectiva normal y muy ambicionada para los soldados. De esta manera Severo alcanzó al mismo tiempo a recuperar el control de un cuerpo militar insubordinado, que habia asesinado a tres emperadores en el espacio de cinco meses, y a ofrecer un nuevo importante aliciente a los legionarios.

Además, èl potenció sensiblemente la guarnición de Roma ${ }^{125}$, porque dobló los efectivos de las cohortes pretorias, elevando los de cada cohorte de quinientos a mil hombres. Lo mismo hizo con las cohortes urbanas y con los caballeros de la guardia imperial (equites singulares. Augustí). Pero la innovación más revolucionaria fue el hecho de que Severo estacionó en Albano, a pocas millas de Roma, una nueva legión, la segunda legión Pártica: por primera vez después de la fin de la guerra civil entre Antonio y Octaviano, una legión se estacionaba establemente en el territorio italiano.

Estas medidas tenian la finalidad no solamente de mejorar el control del centro del poder, contrapesando a los pretorianos con los legionarios, sino también de crear un ejército móbil directamente a los órdenes del emperador; también en este caso el interés del estado era establemente junto a el del emperador, porque este ejército mobil garantizaba una mayor eficiencia militar en la defensa de Italia, pero al mismo tiempo era un instrumento eficaz de exaltación del emperador como jefe, almenos en la dimensión del espectáculo.

En efecto Severo aprestó un poderoso sistema ideológico-propagandístico que le garantizó prestigio, popularidad y consenso, sobre todo a través de un fuerte vinculo religioso entre el ejército y la dinastia. Por eso, quince af̂os después de la muerte de Marco Aurelio, él inventó su propia adopción por parte de aquel emperador, que le permitió enriquecer su propio nombre oficial con la conexión a una serie impresionante de emperadores-dioses: desde el 195 d. de C. Septimio Severo pudo ser nombrado oficialmente en las inscripciones hijo del divino Marco Aurelio y hermano del divino Cómodo (ahora ya rehabilitado), nieto del divino Antonino Pio, tataranieto (pronepos) del divino Adriano, bis-tataranieto (abnepos) del divino Trajano, tris-tataranieto (adnepos) del divino Nerva... Nadie podía decir algo similar.

Al mismo tiempo, su mujer Julia Domna recibió el título de "madre de los cuarteles" o "de las casernas" (mater castrorum), es decir "madre de los soldados"; este título, que ya habia sido otorgado a Faustina menor, la mujer de Marco Aurelio, hoy nos hace sonreir, pero entonces creaba un fuerte vínculo de fidelidad y devoción entre el ejército y toda la dinastia, que resistió más allá de la muerte de su fundador.

Bajo Septimio Severo se multiplicaron las dedicaciones al mumen del emperador, es decir al principio divino que obraba en el emperador, y se afirmó la fórmula con que el dedicante se decia "devoto al principio divino y a la mayestad del emperador y de sus familiares" (devotus mumini maiestatique eius, o bien eorum).

El prestigio militar de Severo, que en realidad él debia a sus generales, fue habilmente exaltado por la insistencia sobre el hecho de que, por primera vez desde el tiempo de Trajano, él había acrecentado el imperio (es decir podía decirse el acrecentador del imperio o propagator imperii), a través de la creación de las nuevas provincias de Osroene y Mesopotamia; de esta manera la propaganda de Severo valorizaba hasta la exageración algunas conquistas que en realidad eran muy limitadas y cuyo mérito militar pertenecía totalmente a sus generales.

Sin embargo, su propaganda presentó a Severo como un nuevo Trajano y un nuevo Alejandro, mejor dicho, como un jefe victorioso superior a Trajano y a Alejandro. Por eso Severo quiso ingresar en la capital pártica Ctesifonte y asumir el título de Pártico Máximo el 28 de enero del 198, es decir en el centésimo aniversario de la subida al poder de Trajano; pero quiso también conquistar a toda costa la fortaleza de Hatra, en el desierto siriano, porque Trajano no habia alcanzado a conquistarla, y él esperaba demostrar así su superioridad. Desgraciadamente su tentativa fracaso dos veces, como nos informa tendenciosamente Casio Dión ${ }^{126}$, pero su propaganda no renunció a representar la conquista de la ciudad para la opinión pública de Roma, y esta escena ha sido reconocida por el investigador francés Gilbert-Charles Picard en los relieves del

i26 C.D, IXXIV, 2,4-6.

125 Hon, III, 13,4.

as C.D. LXXV, 10, 1:11, 1-13.

Revista de Fistoria, año 18, vols, 18-19, 2008-2009, pp. 11-40. 
arco que fue erigido para celebrar la victoria pártica de Severo y que aún se puede ver en el Foro Romano 127 .

La exaltación de Severo explotó también la ocasión de las fiestas seculares (ludi saeculares) celebradas en el 204 d.C., que le permitió presentar su reinado como el comienzo de una nueva edad de oro, según un esquema propagandístico ya probado al tiempo de Augusto, que como Severo las habia celebrado después de la fin de una sangrienta guerra civil y del establecimiento de una dinastia.

Pero el motivo principal del éxito de Severo es el becho de que él supo escoger a los generales más capaces, favorecendo las carreras de hombres de origen humilde, pero con talento militar, que sostuvieron el peso mayor de sus guerras civiles y exteriores, sobre todo con comandos extraordinarios, según el modelo ya elaborado por Marco Aurelio en la edad de la emergencia militar a lo largo del Danubio.

Al mismo tiempo, Severo alcanzó siempre a evitar que la popularidad de sus generales creciera demasiado hasta oscurecer su propio astro. Por eso al tiempo de su segunda guerra pártica eliminó a Julio Leto, cuyo prestigio le parecía humillante y peligroso ${ }^{128}$.

Después de Severo, su hijo Caracalla siguió sustancialmente la misma línea y mantuvo casi intacta esta relación privilegiada con el ejército. Él cometió muchos errores políticos graves, por su presunción que lo llevaba a creerse un gran general y nada menos que un nuevo Alejandro y a escoger mal a sus generales: por eso fue vencido personalmente en Germania ${ }^{129}$ y en la persona de su general Teócrito, un liberto "parvemu", en Armenia ${ }^{130}$. Pero, a pesar de estos errores, mantuvo los pilastros esenciales de la politica de Septimio Severo, resumidas en las últimas palabras dirigidas por el viejo emperador a sus hijos cuando estaba a punto de muerte: «Enriqueced a los soldados, sin preocuparse de los demás» 131 .

En efecto, también Caracalla hizo muchas concesiones a los soldados, con donativos frecuentes y un nuevo aumento del salario ${ }^{132}$. Además, exaltó el orgullo de los militares con su ideologia ecuménica y militarista que calcaba las huellas de Alejandro y preanunciaba la conquista inminente del Oriente, es decir del reino de los Partos.

Esta receta siguió funcionando, porque, a pesar de las derrotas y de la matanza del mismo Caracalla, el ejército se mantuvo fiel a la dinastía y pronto prefirió a Heliogábalo, todavía adolescente, respecto a Macrino, que era un militar maduro y experto.

Esta fidelidad sobrevivió a la desastrosa experiencia del reinado de Heliogábalo y al verdadero trauma ocasionado por su reforma religiosa y se agotó definitivamente sólo después de doce años de desgaste bajo Severo Alejandro. Este emperador, el último de la dinastia de los Severos, ascendido al poder de apenas trece años y sumiso a la autoridad de su madre Julia Mamea, por largo tiempo se quedó "rehén" de los militares, pero cometió el error irremediable de "cambiar el caballo", es decir intentar el regreso a un imperio civil, bajo el control del senado.

Al contrario, Septimio Severo no cometió errores y apostó todo sobre su relación especial con el ejército. Plenamente consciente de sus propios límites como general, él no se expuso incautamente a fracasos ruidosos, sino supo siempre escoger bien a sus generales y mantenecerlos en una posición de subordinación.

$\mathrm{El}$ análisis de sus carreras demuestra que ellos fueron escogidos sólo y exclusivamente por sus efectivas capacidades militares. Entre los generales de Septimio Severo, en efecto, se encuentran hombres de todo tipo de procedencia social y geográfica, que no fueron escogidos ni porque eran compatriotas del emperador, ni porque eran de su misma origen social, sino más bien porque eran capaces y valerosos. Asi encontramos a caballeros ascendidos por el mismo Septimio Severo o ya por Marco Aurelio o Cómodo, y también a senadores que se habian manifestados generales válidos.

Entre los caballeros ascendidos por Severo recuerdo a Lucio Valerio Valeriano, que se mantuvo caballero y llegó a ser prefecto de la nueva provincia de Mesopotamia; Tiberio Claudio Claudiano, que fue admitido en el senado y se convirtió en legado de Panonia Superior (la provincia donde Severo se habia proclamado emperador); Lucio Mario Máximo Perpetuo Aureliano (el Mario Máximo citado como historiador por la Historia Augusta), que también llegó a ser senador y, como Pértinax, llegó a la dignidad de cónsul ordinario por segunda vez y prefecto de la ciudad de Roma.

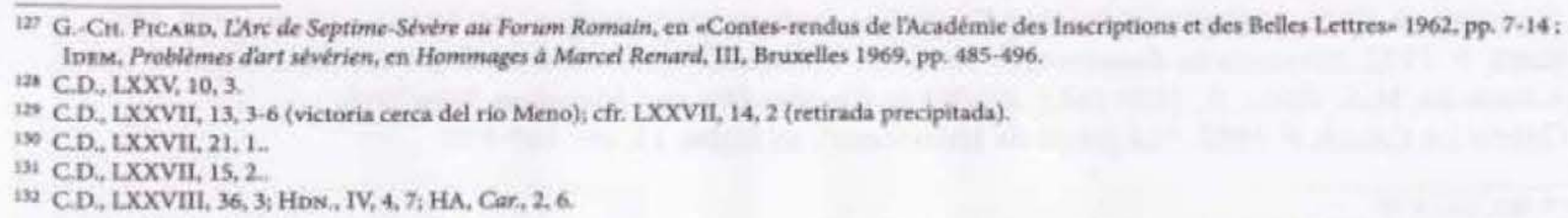


Entre los caballeros ascendidos por Marco Aurelio o Cómodo hay Tiberio Claudio Cándido, y entre los miembros de nobles familias senatoriales hay Publio Cornelio Anulino y Lucio Fabio Cilón. Sin duda Anulino fue escogido también como símbolo, como noble y amigo de Marco Aurelio; pero no habría recibido comandos si no hubiese tenido auténticas capacidades, como podemos constatar en el caso de Quinto Hedio Rufo Loliano Genciano, que era noble y fiel a Severo como Anulino, pero recibió de Severo sólo cargos civiles.

Para escoger a sus generales, Severo no tuvo cuidado ni siquiera del origen geográfico o étnico que tenian. En efecto habia generales itálicos, hispánicos, orientales y también africanos: Lucio Mario Máximo era de Roma; Lucio Valerio Valeriano de Puteoli (actual Pozzuoli, cerca de Nápoles); Lucio Hedio Rufo Loliano Genciano de Liguria; Publio Cornelio Anulino y Lucio Fabio Cilón procedian de España; Tiberio Claudio Pompeyano de Bitinia y Tiberio Claudio Cándido de Numidia (actual Algeria).

Severo no tuvo cuidado ni siquiera de los vinculos de sangre: a su hermano Geta, que esperaba un prestigioso comando en la guerra civil inminente, Severo le impuso quedar en su provincia de retaguardia y no quiso confiarle el comando de una armada 133 .

En conclusión, fueron esta intuición politica y esta fría capacidad de elección que suplieron a la falta de capacidades militares, como en el caso de Augusto, y permitieron a Severo crear una dinastía.

\section{BIBLIOGRAFIA ESCOGIDA}

\section{Casio Dión}

GABBA, E. 1955, "Sulla storia romana di Cassio Dione", en Riv. Stor. Ital. 67, pp. 289-333

GABBA, E. 1959, "Storici greci dell'Impero Romano da Augusto ai Severi", en Riv. Stor. Ital. 71, pp. 361-381 Millar, F. 1965, A Study of Cassius Dio, Oxford 1964 (cfr. la reseña de G. W. Bowersock, en Gnomon 37, pp. $470-473$

MiLLAR, F. 2005, "Rome in Greek culture: Cassius Dio and Ulpian", en TrotANI, L. - ZECCHINI, G. (edd.), La cultura storica dei primi due secoli dell'impero romano (Milano, 3-5 giugno 2004), Roma, pp. 17-40

LETTA, C. 1979, "La composizione dell'opera di Cassio Dione: cronologia e sfondo storico-politico", en TrotANI, L. - NOE, E. - LETTA, C., Ricerche di storiografia greca di età romana, Pisa, pp. 117-189

LETTA, C. 2003, "Documenti d'archivio e iscrizioni nell'opera di Cassio Dione: un sondaggio nella narrazione fino ad Augusto", en Biraschi, A.M. Desideri, P. RoDA, S. ZeCCHINI, G. (ed.), Luso dei documenti nella storiografia antica, Napoli, pp. 597-622

LETTA, C. 2007, "Leruzione del Vesuvio del 202 d.C. e la composizione dell'opera di Cassio Dione", en Athenaeum 95,1 , pp. $41-47$

BARnes, T.D. 1984, "The Composition of Cassius Dio's Roman History", en Phoenix 38, 3, pp. 240-255

Swan, P.M. 1997, "How Cassius Dio composed his Augustan Books. Four Studies", en ANRW, II, 34, 3, Berlin - New York, pp. 2524-2557

Swan, P.M. 2004, The Augustan Succession. An Historical Commentary on Cassius Dio's Roman History Books 55-56 (9 BC-AD 14), Oxford.

\section{Herodiano}

CAssola, F. 1956-1957, "Sull'attendibilità dello storico Erodiano", in "Atti Acc. Pontan.», n.s., 6, pp. 191-200

CAssola, F. 1957, "Erodiano e le sue fonti", en Rend. Acc. Arch. Napoli 32, pp. 165-172

CAssoLA, F. 1957, "Sulla vita e sulla personalità dello storico Erodiano", en Nuova Riv. Stor. 41, pp. 213-223

ALFOLDY, G. 1971, "Herodians Person", en AS 2, pp. 204-233

ALFOLDY, G. 1971, "Zeitgeschichte und Krisenempfindung bei Herodian", en Hermes 99, pp. 429-449

KoLB, F. 1972, Literarische Beziehungen zwischen Cassius Dio, Herodian und der Historia Augusta, Bonn. ANDERSEn, H.A. HoHL, E. 1975 (ed.), Studies in Cassius Dio and Herodian, New York.

Gascó LA CAlle, F. 1982, "La patria de Herodiano", en Habis 13, pp. 165-170

in HA, Sev, 8, 10.

Revista de Historia, año 18, vols. 18-19, 2008-2009, pp. I1-40. 
Gasco, F. 1984, "Las fuentes de la Historia de Herodiano", en Emerita 52, pp. 355-360

GAscó, F. 1987, "El cargo ocupado por Herodiano el historiador", en «Veleia» 4, pp. 365-368

Esprnosa RUiz, U. 1986, "El reinado de Cómodo, Subjetividad y objetividad en la antigua historiografia", en Gerión 57, pp. 113-149

Sidebortom, H. 1997, "The Date od Composition of Herodian's History", en L'Antiquité Classique 66, pp. $271-276$

SiDEBotтom, H. 1997, "Herodian's historical methods and understanding of History", en ANRW, II, 34, 4. Berlin - New York, pp. 2775-2836

Marasco, G. 1997, "Erodiano e la crisi dell'impero", en ANRW, II, 34, 4, Berlin - New York, pp. 2.837-2.927 ZimmermanN, M. 1999, Kaiser und Ereignis. Studien zum Geschichtswerk Herodians, München.

HIDBER, Th. 2006, Herodians Darstellung der Kaisergeschichte nach Manc Aurel, Basel.

\section{Historia Augusta}

Dessau, H. 1889, "Öber Zeit und Persőnlichkeit der Scriptores Historiae Augustae", en Hermes 24, pp. 337392

Dessau, H. 1892, "Über die Scriptores Historiae Augustae", en Hermes 27, pp. 561-605

Dessau, H. 1894, "Die Überlieferung der Scriptores Historiae Augustae", en Hermes 29, pp. 393-416

BAYNES, N.H. 1926, "The Historia Augusta. Its Date and Purpose", Oxford.

BARBIERI, G. 1934, "Il problema del cosiddetto ultimo grande storico di Roma", en Ann. Scuola Norm. Sup.

Pisa, ser. 2, 3, pp. 525-538

BARBIER, G. 1988, "Scritti minori", Roma, pp. 25-93

HARTKE, W. 1940, "Geschichte und Politik im spätantiken Rom. Untersuchungen über die Scriptores Historiae Augustae", Leipzig

MAZZARINo, S. 1951, "Aspetti sociali del IV secolo. Ricerche di storia tardoromana", Roma, pp. 345-370

MAZZARINo, S. 1983, "Il pensiero storico classico", III, Bari, pp. 214-247

Momigliano, A. 1960, "An unsolved Problem of Historical Forgery: the Scriptores Historiae Augustae", en IDEM, "Secondo contributo alla storia degli studi classici e del mondo antico", Roma, pp. 105-143

ALFOLDI, A. 1952, A Conflict of Ideas in the Late Roman Empire. The Clash between the Senate and Valentinian $I$, Oxford

Straub, J. 1952, Studien zur Historia Augusta, Bern.

STRAUB, J. 1963, Heidnische Geschichtsapologetik in der christlichen Spätantike. Untersuchungen über die Zeit und Tendenz der Historia Augusta, Bonn.

SteRN, H. 1953, Date et destinataire de l'Histoire Auguste, Paris

SYME, R. 1968 (reprint 2001), Ammiamus and the Historia Augusta, Oxford.

SYME, R. 1971, Emperors and Biography. Studies in the Historia Augusta, Oxford.

SYME, R. 1971, The Historia Augusta. A Call of Clarity, Bonn.

SYMF, R. 1983, Historia Augusta Papers, Oxford.

Chastagnot, A. 1970, Recherches sur l'Histoire Auguste, Bonn.

JOHNE, K.P. 1976, Kaiserbiographie und Senatsaristokratie. Untersuchungen zur Datierung und sozialen Herkunft der Historia Augusta, Berlin.

BARNeS, T.D. 1978, The Sources of the Historia Augusta, Bruxelles.

KoLB, F. 1987, Untersuchungen zur Historia Augusta, Bonn.

Scherthauer, A. 1987, Kaiserbild und literarisches Programm. Untersuchungen zur Tendenz der Historia Augusta, Frankfurt.

BENARIO, H.W. 1997, "Ignotus", the "good biographer"?, en ANRW, II, 34, 3, Berlin - New York, pp. 2.759 2.772

BIRLEY, A.R. 1997, Marius Maximus the consular biographer, en ANRW, II, 34, 3, Berlin - New York, pp. 26782757

LıPPoLD, A. 1998, Die Historia Augusta. Eine Sammlung römischer Kaiserbiographien aus der Zeit Konstantins, Stuttgart. 


\section{Septimio Severo y su dinastía}

Platnaver, M. 1918, The Life and Reign of the Emperor Lucius Septimius Severus, London.

HASeBroek, J. 1921, Untersuchungen zur Geschichte des Kaisers Septimius Severus, Heidelberg.

HAMmoND, M. 1940, "Septimius Severus, Roman bureauerat", en HSCPh 51, pp. 137-173

CALDERINI, A. 1949, I Severi. La crisi dell impero nel III secolo, Bologna.

WALSER, G. 1973, "Die Beurteilung des Septimius Severus in der älteren und neueren Forschung", en Mus. Helv. 30, pp. 104-116

WALSER, G. 1975, "Die Severer in die Forschung 1960-1972", en ANRW, II, 2, Berlin - New York, pp. 614-656 BIRLEY, A.R. 1988, The African Emperor Septimius Severus, London

SONSKES-THOMPSON, J. 1990, Aufstände und Protestaktionen im Imperium Romanum. Die severischen Kaiser im Spannungsfeld innerpolitischer Konflikte, Bonn.

Letra, C. 1991, La dinastia dei Severi, en Momiglano, A. - Schiavone, A. (edd.), Storia di Roma, II, 2, Torino, Einaudi, pp. 639-700

GrANT, M. 1996, The Severans. The Changed Roman Empire, London - New York.

Christol, M. 1998, L'Empire romain du III' siècle. Histoire politique 193-325 après J.-C., Paris

DAL Covolo, E. - RINALdI, G. (ed.) 1999, Gli imperatori Severi: storia, archeologia, religione, Roma.

Daguet-Gager, A. 2000, Septime Sévère. Rome, I'Afrique, l'Orient, Paris.

Bowman, A. - CAmeron, A. - Garnsey, P. (edd.) 2006, The Cambridge Ancient History, XII, The Crisis of the Empine, AD 193-337, Cambridge.

SPIE⿺vocel, J. 2006, Septimitus Severus, Darmstadt.

\section{La familia de Septimio Severo y su carrera hasta el 193 d. de C.}

BeRSANETtI, G.M. 1946, "Il padre, la madre e la prima moglie di Settimio Severo", en Athenaeum 24, pp. $28-43$

Auricemma, S. 1950, "Lavo paterno, una zia ed altri congiunti dell'imperatore Severo", en Quad. Arch. Lib. 1, pp. 59-77

GueY, J. 1951, "L'inscription du grand-père de Septime Sévère à Lepcis Magna", en Mém. Soc. Nat. At. Fr. 82 , pp. $161-226$

RoMAnel.LI, P. 1958, "Fulvii Lepcitani", en Arch. Class. 10, pp. 258-261

Di Vita Évrard, G. 1963, "Un "nouveau" proconsul d'Afrique parent de Septime Sévère, Caius Septimius Severus", en MEFRA 75, pp. 389-414

BARNES, T.D. 1967, "The Family and Career of Septimius Severus", en Historia 16, pp. 87-107

BIRLEY, A.R. 1970, "Some notes on HA Severus, 1-4", en Bonner Hist. Aug. Coll. 1968-69, Bonn, pp. 59-77 Herzig, H. 1972, "Die Laufbahn des Septimius Severus, Sufes, and das Stadtrecht von Lepcis magna", en Chiron 2, pp. 393-404

COLEMAN, K.M. 1983, "An African at Rome. Statius, Silvae 4.5", en PACA 17, pp. 85-99

LETTA, C. 1987, La famiglia di Settimio Severo, en L'Africa romana, IV (Sassari 1986), Sassari, pp. 531-545

Chausson, F. 1998, "Une hypothèse sur la grand-mère maternelle de Septime Sévère", en Latomus 57, pp. $391-414$

Chausson, F. 2002, "Variétés généalogiques. I, Marc Aurèle et Numa Pompilius. II, Macer, avus maternus de Septime Sévère", en Historiae Augustae Colloquium Perusimum (Perugia, 1-4 giugno 2000), Bari, pp. 149-170 C. LETTA 2008, "Ancora sulla famiglia di Settimio Severo : nota testuale a HA, Sev., 1, 1-2", en ARDUINI, P. - Audano, S. - Borghini, A. (edd.), Studi offerti ad Alessandro Penutelli, Roma, pp. 107-113

\section{El pronunciamiento de 193 d.C.}

DomAszewsKI, A. von 1898, "Der Staatsstreich des Septimius Severus", en Rh. Mus. 53, pp. 638-639

BIRIEY, A.R. 1969, "The Coups d'État of the Year 193", en Bonner Jahrbücher 169, pp. 247-280

Champlin, E. 1979, "Notes on the Heirs of Commodus", en Amer. Journ. Philoll00, pp. 288-306

BiRD, H.W. 1989, "A strange aggregate of errors of AD 193", en Class. Bull. 65, pp. 95-98

SCHETrino, M.T. 2000, "Lopposizione politica all'ascesa di Settimio Severo", en SoRD1, M. (ed.), L'opposizione 
nel mondo antico (Contrib. Ist. St. Ant., 26), Milano, pp. 261-280

SChettino, M.T. 2001, "Cassio Dione e le guerre civili di età severiana", en Gerión 19, pp. 533-558

SLAviCH, C. 2001, "Pólemoi kai stáseis. "Propaganda severiana" nell'opera di Cassio Dione", en SCO 47, 1 , ed. 2004, pp. 131-166

\section{Pertinax}

HoHL, E. 1956, "Kaiser Pertinax und die Thronbesteigung seines Nachfolgers im Lichte der Herodiankritik", Sitz.-Ber. Deutsch. Akad. Wiss. Berlin, 2, pp. 1-32.

PFL.AuM, H.-G. 1960, Les carrières procuratoriennes équestres sous le Haut-Empire romain, Paris, pp. 451454, nr. 179.

KOLBE, H.G. 1962, "Der Pertinaxstein aus Brühl", en BJ 162, pp. 407-420.

KOLBE, H.G. 1964, Die ritterliche Laufbahn des Kaisers Pertinax, en Akten des IV. Int. Kongress für griechischen und lateinischen Epigraphik, Wien, pp. 185-191.

Cassola, F. 1965, "Pertinace durante il principato di Commodo", en Par. Pass. 20, pp. 451-477.

Grosso, F. 1966, "Tertulliano e l'uccisione di Pertinace", en Rend. Acc. Linc., ser. 8a , 21, pp. 140-150

ALFOLDY, G. 1974, "P. Helvius Pertinax und M. Valerius Maximianus", en Situla 14-15, pp. 199-215.

ID. 1987, Römische Heeresgeschichte, Beîräge 1962-1985, Amsterdam, pp. 326-348).

Beranger, J. 1978, Pertinax et les "alimenta", en Bonner Hist. Aug. Coll. 1975-76, Bonn, pp. 75-86 (v. anche BIRLEY, A.R., ibid, pp. 87-90).

LAmBogl.1A, N. 1976-1978, "L'azienda e la patria d'origine dell'imperatore Pertinace", en Riv. Ing. Intem. 31-33, pp. 1-5.

Lo CAsCio, E. 1980, "Gli "alimenta" e la "politica economica" di Pertinace", en Riv. Fil. Istr. Class. 108, 3, pp. 264-288.

Lippold, A. 1980, "Pertinax in Rătien?", en Zeitschr. Papyr. Epigr. 38, pp. 203-215.

Lippold, A. 1983, "Zur Laufbahn des P. Helvius Pertinax", en Bonner Hist. Aug. Coll. 1979-1981, Bonn, pp. 173-191.

SORACI, R. 1984, "Lopera legislativa di Pertinace", en Quad. Catan. 6, pp. 315-336.

Soracr, R. 1986, "Voluntas domini" e gli inquilini-coloni sotto Commodo e Pertinace, ibid., 8, pp. $261-339$

DeviJver, H. 1988, "Les "militiae equestres" de P. Helvius Pertinax, en Zeitschr. Papyr. Epigr. 75, pp. 207. 214.

Milazzo, S. 1988, Pertinacis natalis imperii, en Studi in onore di Cesare Sanfilippo, VII, Milano, pp. 437-461 Garzón Blanco, J.A. 1990, El emperador Publio Helvio Pertinax y la crisis del año 193, Málaga.

ZYROMSKI, M. 1991, "Specialization in the Roman provinces of Moesia in the time of principate", en Athenaeum 79, 1, pp. 59-102, particularmente pp. 81-83.

Montero, S.,"Materiales para el estudio de la religión y la politica religiosa del emperador Pertinax", en Mangas, J. - Alvar, J. (edd.) 1996, Homenaje a J.M. Blázquez, III, Historia de Roma, Madrid, pp. 147-164

\section{Los generales de Septimio Severo}

Graham, A.J. 1973, "Septimius Severus and his Generals AD 193-197", en Foot, M.R.D. (ed.), War and Society. Essays in honor of J.R. Western, pp. 255-275 e 336-345.

FAURE, P. 2002, "L'entourage militaire des empereurs Sévères en campagne (193-235 ap. J.-C.), en Cahiers du Centre d'Études d'Histoire de la Défense, 18, pp. 5-48.

(http://www.cehd.sga.defense,gouv.fr/publications/cahier18,pdf).

EcK, W. 1981, "Miscellanea prosopographica", en Zeitschr. Papyr. Epigr. 42, pp. 227-238, particularmente 254-256 (por la origen de Ti. Claudio Claudiano).

Piso, I. 1982, La carrière de Ti, Claudius Claudianus, in Epigrafia e ordine senatorio, 1 ("Tituli", 4), Roma, pp. 167-176.

HESNARD, A. 1999, "Claudius Claudianus cl. vir, propriétaire víticole campanien et navicularius alexandrin", en Pallas 50, pp. 11-26.

KenNeDY, D.L. 1979, "Ti. Claudius Subatianus Aquila, "first prefect of Mesopotamia", en Zeitschr. Papyr. Epigr. 36, pp. 255-286. 
ALFOL.DY, G. 1987, "Die Inschriften des P. Cornelius Anullinus und seine Tãtigkeit im römischen Deutschland, en Fundberichte aus Baden- Württenberg 12, pp. 303-324

Cristol, M. 1981, "La carrière de Q. Hedius Rufus Lollianus Gentianus", en Revue Étud. Anc. 83, 1-2, pp. $75-84$

DUnCan-Jones, R.P. 1969, "Praefectus Mesopotamiae et Osrhoenae", en Class. Phil. 64, pp. 229-233 y 65 (1970), pp. 107-109 [sobre L. Valerio Valeriano]

FIrZ, J. 1972, Les Syriens à Intercisa, Bruxelles, pp. 204-218 [sobre L. Valerio Valeriano]

Magioncalda, A. 1982, Testimonianze sui prefetti di Mesopotamia (da Settimio Severo a Diocleziano), en Studia et Documenta Historiae et luris 48, pp. 167-238 (sobre L. Valerio Valeriano pp. 188-201)

SPEIDEL, M.P. 1985, "Valerius Valerianus in charge of Septimius Severus' Mesopotamian Campaign", en Class. Phil. 80, pp. 321-326 (= Id., Roman Army Studies, II, Stuttgart 1992, pp. 218-223)

ECK, W. 1996, en Zeitschr. Papyr. Epigr. 113, pp. 129-143 [sobre L. Valerio Valeriano]

\section{Septimio Severo y el ejército}

PASserinI, A. 1944-45, "Gli aumenti del soldo militare da Commodo a Massimino", en Athenaeum, n.s., 22-23, pp. 145-159.

BIRLEY, E. 1969, "Septimius Severus and the Roman Army", en Epigraphische Studien 8, pp. 63-82.

GARNSEY, P. 1970, "Septimius Severus and the Marriage of the Soldiers", en CSCA 3, pp. 45-53.

Dever.r, R. 1971, "The Army Pay Rises under Severus and Caracalla, and the Question of Annona militaris", en Latomus 30, pp. 687-695.

SMITH, R.E. 1972, "The Army Reforms of Septimius Severus", en Historia 21, pp. 481-500.

CAMPBEIL, B. 1978, The Marriage of the Soldiers under the Empire, en «Journ. Rom. Stud.» 68, pp. 153-166

KenNEDY, D.L. 1978, Some Observations on the Praetorian Guard, en "Anc. Soc.» 9, pp. 297-301.

LE Roux, P. 1992, L'armée romaine sous les Sévères, en «Zeitschr. Papyr. Epigr.» 94, pp. 261-268.

\section{Propaganda}

RuBin, Z. 1980, Civil War Propaganda and Historiography, Bruxelles.

BAhARAL, D. 1989, "Portraits of the Emperor L. Septimius Severus (193-211 AD), as an Expression of his Propaganda", en Latomus 48, pp. 566-580.

RAFDER, J. 1992, "Herrscherbildnis und Münzpropaganda: zur Deutung des "Serapistypus" des Septimius Severus", en JDAI 107, pp. 175-196.

BaHARAL, D. 1996, Victory of Propaganda. The dynastic Aspect of Imperial Propaganda of the Severi. The literary and archaeological Evidence AD 193-235 (BAR, Int. Ser., 657), Oxford.

Lovortr, F. 1998, "Per un arricchimento della documentazione originaria della genealogia "antonina" di L. Settimio Severo", en Riv, Stor. Ant. 28, pp. 221-227. 